\title{
A Statistical Study of Aftershock Sequences
}

\author{
G. RANALLI $\left(^{*}\right)$
}

Ricevuto il 9 Novembre 1969

Summary. - A comprehensive statistical study of the phenomenology of aftershock sequences is made in this paper. The spatial distribution of aftershocks indicates that they are mainly crustal events; however, deeper sequences also take place. The analysis of the distribution of aftershocks in 15 sequences with respect to time and magnitude leads to the statistical confirmation of a set of phenomenological laws describing the process, namely, the time-frequency law of hyperbolic decay of aftershock activity with time, the magnitude stability law, and the exponential mag. nitude-frequency distribution. The hypotheses involved are checked. The grouping of data and the statistical methods employed are chosen according to some basic well-confirmed assumptions regarding the nature of the process.

Riassunto. - Questo articolo presenta un completo studio statistico della fenomenologia delle serie di repliche di terremoti. La distribuzione spaziale degli ipocentri delle repliche indica che si tratta di un processo che interessa principalmente la crosta terrestre; tuttavia non mancano esempi di serie di repliche profonde. L'analisi della distribuzione delle repliche in 15 serie rispetto al tempo e alla magnitudo conferma le leggi statistiche che descrivono lo sviluppo di una serie: la frequenza delle repliche decresce iperbolicamente nel tempo, la magnitudo è stabile nel tempo, e la distribuzione della magnitudo è esponenziale. Le ipotesi considerate sono sottoposte ad esame. La classificazione dei dati e i metodi statistici impiegati sono scelti in base ad alcune ipotesi che sono state ampiamente confermate.

(*) University of Illinois, Urbana, Illinois; now at the Atlantic Oceanographic Iaboratory, Bedford Institute, Dartmouth, Nova Scotia, Canada. 


\section{IXTRos)Lerex.}

A romprehensive study of the phenomenology of aftershock serpuences must, include space, time, and mannitude distributions. Sequences which ocenred in many parts of the world have been studied by various anthors and the results are scattered in the geophysical literature. The determination of the phenomenological laws describing the aftershock process is a statistical problem, and it is therefore desirable to employ a consistent statistical procedure and to perform appropriate fests. We feel that some of the methods employed in the past were not rigorous; consequentily, this faper is an attempt to present a mified procedure for the statistical sturly of aftershock serfuences. For this purpose, 15 serpuences have been analyzed in detail, even if some of them had already been studied according to different methods.

The study of the space distribution of aftershocks within a given secpuence does not present particular problems. Its accuracy depends on the precision with which epicentral roordinates and focal depths are computed. It has been maintained (1) that aftershocks are essentially a shallow phenomenon. A review of available information partly confirms this view, but allowance must be made for notable (exceptions.

The situation is more complicated with respect to time and mannitude alistribution. The problem is besionlly that of finding a statistical relationship between the various quantities involved, and of estimating the parameters appearing in the statistical laws. First of all, when examining the data (which consist of the origrin times $t_{i}$ and of the individual magnitudes $H_{t}$ of the aftershocks), one must be reasonably sure to be dealing with a romplete set; that is, ideally no aftershock with $l I \geqslant I^{*}$, where $I^{*}$ is the minimum magnitude detected in a serpuence, should be missing in the time interval considered. Moreover, it has been shown empirically by Suzuki $\left(^{2}\right)$ that the mode of grouping the data influences the results: therefore the mode of gromping should be as uniform as possible. Finally, it is desirable to monploy a statistical procedure that does not contradict the underlying characteristics of the phenomenon observed, it is necessary to apply some statistical test to check the hypothesis being entertained, and confidence limits on the results must be given. Nore of ten than not, one or several of these conditions are not met in the stindy of 
Table I - List of Aftershock Sequences Selected for Detailed Study.

\begin{tabular}{|c|c|c|c|c|c|c|c|c|c|c|c|c|c|}
\hline Sequence & Region & Reference & & $t_{o}$ & \multicolumn{2}{|l|}{$\varphi_{0}$} & $\lambda_{0}$ & \multicolumn{2}{|c|}{$h_{0}$} & $M_{0}$ & $M^{*}$ & $h$ & $K$ \\
\hline 1. Alaska 1964 & Alaska & Page $\left({ }^{3}\right)$ & Mar & $28,03: 36: 13$ & $61.0^{\circ}$ & $\mathrm{N}$ & $147^{\circ} .8 \quad W$ & 20 & $\mathrm{~km}$ & 8.5 & 4.5 & $<35 \mathrm{~km}$ & 294 \\
\hline 2. Aleutian I. 1957 & Aleutian I. & Duda $\left({ }^{4}\right)$ & Mar & $9,14: 22: 28$ & $51 .{ }^{\circ} 3$ & $\mathrm{~N}$ & $175^{\circ} .8 \mathrm{~W}$ & 一 & & 8.3 & 5.9 & $<150 »$ & 205 \\
\hline 3. Long Beach 1933 & California & Benioff $\left({ }^{5}\right)$ & Mar & $10,17: 54: 08$ & $33^{\circ} 34^{\prime}>$ & & $117^{\circ} 59^{\prime} \mathrm{W}$ & & low & 6.3 & 3.9 & shallow & 78 \\
\hline 4. Desert Hot Sp. 1948 & $"$ & Richter et al. $\left({ }^{6}\right)$ & Dec & $4,15: 43: 17$ & $33^{\circ} 56^{\prime} \mathrm{S}$ & & $116^{\circ} 23^{\prime} \mathrm{W}$ & sha & low & 6.5 & 3.0 & $<35 \mathrm{~km}$ & 68 \\
\hline 5. Kern County 1952 & 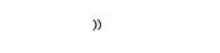 & Richter ( $\left.{ }^{7}\right)$ & Jul & $21,11: 52: 14$ & $35^{\circ} .0^{\prime} \mathrm{N}$ & & $119^{\circ} 02^{\prime} \mathrm{W}$ & 16 & $\mathrm{~km}$ & 7.7 & 4.0 & shallow & 184 \\
\hline 6. San Francisco 1957 & $"$ & Tocher $\left({ }^{8}\right)$ & Mar & $22,19: 44: 21$ & $37^{\circ} 40^{\prime} \mathrm{S}$ & & $122^{\circ} 29^{\prime} \mathrm{W}$ & sha & low & 5.3 & 2.0 & $<10 \mathrm{~km}$ & 160 \\
\hline 7. Salinas 1963 & ” & Udias $\left({ }^{9}\right)$ & Sept & $14,19: 46: 17$ & $36^{\circ} 52^{\prime} \mathrm{\perp}$ & & $121^{\circ} 38^{\prime} \mathrm{W}$ & 3.3 & $\mathrm{~km}$ & 5.4 & 1.0 & $<14$ & 46 \\
\hline 8. Parkfield 1966 & $"$ & McEvilly et al. $\left({ }^{10}\right)$ & Jun & $28,04: 26: 13$ & $35^{\circ} 57^{\prime} \mathrm{S}$ & & $120^{\circ} 29^{\prime} \mathrm{W}$ & sha & low & 5.5 & 2.0 & $<12 》$ & 173 \\
\hline 9. Chalkidike 1932 & Greece & Papazachos et al. $\left({ }^{11}\right)$ & Sept & $26,19: 20: 37$ & $40^{\circ} .5$ & & $23^{\circ} .7 \quad \mathrm{E}$ & 28 & $\mathrm{~km}$ & 6.9 & 3.4 & shallow & 85 \\
\hline 10. W. Thessaly 1954 & $"$ & $\eta$ & Apr. & $30,13: 02: 36$ & $39^{\circ} .3$ & $\mathrm{~N}$ & $22^{\circ} 2 \mathrm{E}$ & 19 & ” & 7.0 & 3.2 & ») & 299 \\
\hline 11. Amorgos 1956 & $"$ & $"$ & Jul & $9,03: 11: 40$ & $36^{\circ} .7$ & $\mathrm{~N}$ & $25^{\circ} .8 \mathrm{E}$ & 21 & $"$ & 7.5 & 3.5 & $"$ & 400 \\
\hline 12. Magnesia 1957 & ” & 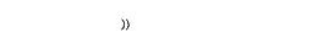 & Mar & $8,12: 21: 13$ & $39^{\circ} .3$ & $\mathrm{~N}$ & $22^{\circ} .6 \mathrm{E}$ & 18 & $"$ & 6.8 & 3.0 & $"$ & 291 \\
\hline 13. Zante 1962 & $"$ & $"$ & Apr & $10,21: 37: 13$ & $37^{\circ} .6$ & $\mathrm{~N}$ & $20^{\circ} .1 \mathrm{E}$ & 20 & ” & 6.3 & 3.6 & $"$ & 139 \\
\hline 14. Cremasta 1966 & $n$ & Comninakis et al. $\left({ }^{12}\right)$ & Feb & $5,02: 01: 43$ & $39^{\circ} .1$ & $\mathrm{~N}$ & $21^{\circ} .6 \mathrm{E}$ & 20 & ” & 5.9 & 3.4 & $"$ & 103 \\
\hline 15. Hawke's Bay 1931 & New Zealand & Benioff $\left({ }^{5}\right)$ & Feb & $3,10: 15: 00$ & $39^{\circ} .5$ & S & $177^{\circ} .0 \mathrm{E}$ & - & & 7.6 & 4.1 & - & 71 \\
\hline
\end{tabular}


aftershock sequences, and the significance of the results is therefore debatable.

Among the several sequences for which origin times and magnitude of individual aftershocks have been published, 15 have been selected for detailed study. As far as possible we have tried to include sequences from different geographic regions, even if this implied considering a few sequences whose completeness may be in doubt. Since the determination of the statistical laws is more reliable when data are more abundant, no aftershock sequence consisting of less than 46 shocks has been included.

Table I lists the aftershock sequences whose time and magnitude distributions are studied in this paper; it includes region of occurrence, literature reference, main shock parameters ( $t_{0}$ origin time; $\phi_{0}, \hat{\lambda}_{0}$ geographic coordinates; $h_{0}$ focal depth; $h_{0}$ magnitude), minimum magnitude of aftershock included $\left(M^{*}\right)$, focal depth of aftershocks $(h)$, and total number $K$ of aftershocks with $. I \geqslant M^{*}$ recorded in the first 100 days. (In sequence (1) the first day after the main shock is excluded from the (rount.) Focal depths are in kilometers; the term "shallow" is taken to mean "crustal", and often (especially in California) " upper crustal". Magnitude are given in the $I I$-scale or $M_{L_{0}}$-scale, with the exception of sequence (1), where the m-scale has been employed.

It will be seen that the results of the analysis confirm the 3 basic laws describing the phenomenology of aftershock sequences, namely, the time-frequency law (Omori's law) as formulated by Mogi $\left({ }^{13}\right)$, the magnitude stability law $\left({ }^{14}\right)$, and the magnitude-frequency law $\left({ }^{15}\right)$.

\section{Spatial Destribution of Aftershocks.}

The spatial distribution of the shocks in an aftershock sequence is naturally related to the location of the main shock. The following considerations are based on a comprehensive survey of available data and are not limited to the sequences listed in Table I. If one traces on a map the boundary of the area in which the epicenters are located, the epicenter of the main shock is usually rlose to this boundary. Such is the case for all aftershock sequences of large earthquakes wich occurred in Japan from 1923 to $1963\left({ }^{16}\right)$. When aftershock activity takes place along a fault segment, as is frequently the case in California, the domain of the epicenters is approximately elliptical 
with the long axis parallel to the aretive fault segment; often the main shock ocempies, roughly speaking, one focus of the ellipse, and the aftershocks are concentrated toward the two ends. In some sequences the aftershock epicenters are clustered in a very small area (only a few kilometers in length and width), but this is rather exceptional; uswally they are spreacl out over a much larger area. In the aftershock sequence of the Alentian Islands earthquake of March 9, 1957 (4) the distribution of the epicenters follows closely the trend of tectonic activity along the Alentian are.

As to the focal depths of aftershocks, a review of available data by Page ${ }^{1}$ ) indicates that, when hypocenter determinations are accurate, aftershocks are shallow events following a main shock which is itself shallow. Aftershock sequences therefore appear to be crustal phenomena, with the majority of shocks clustering in the mper layer of the crust $(h \leqslant 20 \mathrm{~km})$.

There are, however, some exceptions. In the region of Greece, the Southern Sporades earthquake of Irarch 18, 19:6 had a reported depth of $50 \mathrm{~km}$ and was followed by 18 aftershorks with $M \geqslant 3.9$ which were recorded in Athens; the sequence of the Anatolia earthquake of March $18,1953(h=50 \mathrm{~km})$ comprised 21 aftershocks in the first 13 days; the sequence of the Zante earthquake of November 15 , $1959(h=55 \mathrm{~km})$ consisted of 18 shocks; the focal depths of individual aftershocks, however, were not determined (11). In the aftershock sequence of the Kamchatka earthquake of November 4, 195: the majority of shocks were located near the Mohorovicic discontinuity, but some of them had foci as deep as $60 \mathrm{~km}\left({ }^{17}\right)$. The sequence following the Alentian Islands earthquake of March 9, 1957 had an average focal depth of $74 \mathrm{~km}$, and individual shocks were as much as $150 \mathrm{~km}$ deep $\left({ }^{4}\right)$.

Two more notable exceptions have occurred in Romania and in Central Asia. Iosif and Radu $\left({ }^{18}\right)$ have studied the aftershock sequence following an earthquake with $M=7.4$ and $h-150 \mathrm{~km}$ that took place in the region of Vrancea, Romania, on November 10, 1940. The focal depths of aftershocks $(3.3 \leqslant M \leqslant 5.5)$ were of the same order. Iukk (19) has studied the aftershock sequence of the Dzhurm earthquake of March 14,1965 , which occurred in the Pamir-Hindu Kush region and had a focal depth of $210 \mathrm{~km}$. The observation period lasted for about 22 days, during which 390 aftershocks were recorded; their focal depths increased in time from 200 to more than $2.10 \mathrm{~km}$. 
The examples of recorded subcrustal aftershock sequences, however, form a very small part of the total number of sequences known to date; on the other hand, subcrustal earthquakes are themselves much less numerous than crustal ones. Therefore the comparative index of aftershock activity should be given by the ratio of the pereentages of crustal and subcrustal earthquakes which are followed by a sequence. At present there is a bias due to instrumentation which farours the detection of shallow aftershock sequences whereas deep ones may go undetected. Thus, the conchusion that aftershocks are generally it shallow phenomenon has to be accepted and at the same time it must be ralized that exceptions exist and that the data are far from complete.

\section{THME DISTRIBLTION OF AFTFRSIOCKS.}

It is customary to regard aftershocks as random events in time, whose frequency is governed by some time-decay law. Jeftreys $\left({ }^{20}\right)$, in a study of the aftershocks of the Tango, Japan, earthquake of March $\tau, 1927$, found no sign of mutual dependence between aftershorks. That is, there was no indication that the chance of an aftershock in a given interval of time depended on anything but the time since the main shock, the aftershock frequency falling of with time according to Omori's law. The observed frequency showed only random departures from the law. It has since become a commonly arcepted fact that aftershocks can be regarded as random independent events. It follows that any mathematical relationship relating time and frequency must not be interpreted as a physical "law" griving an exact correspondence, but as a statistical law of chance which is followed "on the average" observed frequencies showing random fluctuations from the theoretically expected values.

The fact that aftershock sequences consist of independent random events does not imply that they are a simple Poisson process. In a simple Poisson process the probability of occurrence of one erent in a given time interval is constant for all $t$; this is obvionsly not the case for aftershocks, where the probability of occurrence depends on the time elapsed since the main shock. But, as Jeffreys (20) and many others have established, apart from the common dependence upon the main shock, no further mutual relation is found within the sequence. 
In this section the statistical decay law of aftershock activity is estimated for the 15 sequences listed in Table $I$. The data have been grouped according to a procedure suggested by Utsu $\left({ }^{-1}\right)$. The origin time $t_{0}$ of the main shock has been taken as origin of the time axis, $t_{0}=0$. The origin times $t_{i}$ of the aftershocks, obtained from the reference listed in Table I, have been expressed in terms of days after the main shock. The first day has been excluded from the analysis because of its possible incompleteness with respect to the number of shocks counted, due to the high frequency of aftershocks. Usually, aftershocks occurring in the time interval $1 \leqslant t \leqslant 100$ have been considered, unless a sequence comes to an end in a period of time shorter than 100 days. The time axis has been divided into logarithmically uniform intervals, such that their boundaries $t_{i}^{*}$ satisfy the relation

$$
\log t_{i}^{*}=0.1 i, \quad i=0,1, \ldots, 20 .
$$

Now, if $N_{i}$ is the number of aftershocks occurring in the time interval $\Delta t_{i}^{*}=t_{i+1}^{*}-t_{i}^{*}$, the quantity

$$
n_{i}=\frac{N_{i}}{\Delta t_{i}^{*}}
$$

represents the observed frequency per mit time interval. This observed frequency is associated with the centered value of the time interval concerned

$$
t_{i}=\frac{t_{i}^{*}+t_{i+1}^{*}}{2}
$$

so that one obtains a set of points $\left(t_{i}, n_{i}\right)$ in the $(t, n)$-plane. The data arranged in this fashion are shown in Table I.I, the first column representing the centered time, the second the number of shocks in the time interval concerned, and the third the observed frequency. In the sequences(4), (7), (10), (12), (13) and (15), in which the number of shocks in some of the original time intervals was zero, the time intervals have been grouped two by two and $n_{i}$ and $t_{i}$ have been calculated accordingly.

The $\left(t_{i}, n_{i}\right)$-points usually show an approximately linear trend on doubly logarithmic paper. Consequently, it is reasonable to assume that the frequency of aftershocks per unit time $"$ and the time $t$ are related by an equation of the form

$$
n(t)=\alpha t^{\beta}
$$


Table II - Observed Frequenct of Altershocks.

\begin{tabular}{|c|c|c|c|c|c|}
\hline$t_{i}$ & $N_{i}$ & $n_{i}$ & $t_{i}$ & $X_{i}$ & $n_{i}$ \\
\hline \multicolumn{3}{|c|}{ (1) Alaska 1964} & 2.837 & 2 & 3.075 \\
\hline 1.129 & 19 & 73.379 & $\begin{array}{l}3.572 \\
+496\end{array}$ & $\frac{2}{3}$ & $\begin{array}{l}2,443 \\
2,010\end{array}$ \\
\hline 1.422 & 17 & 52.154 & $\begin{array}{l}4.496 \\
5.661\end{array}$ & $\begin{array}{l}3 \\
1\end{array}$ & $\begin{array}{l}2.910 \\
0.771\end{array}$ \\
\hline 1.790 & 18 & 43.863 & 7.126 & $\begin{array}{l}1 \\
1\end{array}$ & $\begin{array}{l}0.771 \\
0.612\end{array}$ \\
\hline 2.254 & 16 & 30.970 & 8.972 & 2 & 0.972 \\
\hline 2.837 & 19 & 29.213 & 11.295 & I & 0.386 \\
\hline 3.572 & 13 & 15.877 & 14.219 & 1 & 0.307 \\
\hline 4.496 & 13 & 12.612 & 17.901 & 1 & 0.244 \\
\hline 5.661 & 12 & 9.247 & & & \\
\hline 7.126 & 19 & 11.630 & \multirow{2}{*}{\multicolumn{3}{|c|}{ (4) Desert Hot Spring 1948}} \\
\hline 8.972 & 11 & 5. 348 & & & \\
\hline 11.295 & 10 & 3.862 & & 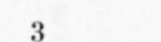 & 5.129 \\
\hline 14.219 & 17 & 5.215 & $\begin{array}{l}1.292 \\
2.048\end{array}$ & $\begin{array}{l}3 \\
2\end{array}$ & 2.158 \\
\hline 17.901 & 22 & 5.361 & $\begin{array}{l}2.048 \\
3.246\end{array}$ & 4 & $\begin{array}{l}2.158 \\
2.723\end{array}$ \\
\hline 22.536 & 19 & 3.678 & $\begin{array}{l}3.246 \\
5.145\end{array}$ & 7 & \\
\hline 28.371 & 6 & 0.923 & 5.145 & & 3.006 \\
\hline 35.717 & 13 & 1.588 & 8.155 & 8 & 2.168 \\
\hline 44.965 & 15 & 1.455 & 12.924 & 3 & 0.513 \\
\hline 56.607 & 13 & 1.002 & 20.484 & 5 & 0.539 \\
\hline 71.264 & 9 & 0.551 & 32.465 & 5 & 0.340 \\
\hline 89.716 & 13 & 0.632 & 51.453 & 1 & 0.043 \\
\hline & & & 81.548 & 3 & 0.081 \\
\hline \multicolumn{3}{|c|}{ (2) Aleutian I. 1957} & \multirow[b]{2}{*}{ (5) Kern } & \multirow{2}{*}{ County } & \multirow[b]{2}{*}{1952} \\
\hline 1. 129 & 6 & 23.172 & & & \\
\hline 1.422 & 9 & 27.611 & 1.129 & 5 & 19.310 \\
\hline 1.790 & 4 & 9.747 & 1.422 & 7 & 21.475 \\
\hline 2.254 & 6 & 11.614 & 1.790 & 11 & 26.805 \\
\hline 2.837 & 9 & 13.838 & 2.254 & 13 & 25.163 \\
\hline 3.572 & 9 & 10.992 & 2.837 & 7 & 10.763 \\
\hline 4.496 & 6 & 5. 821 & 3.572 & 3 & 3.664 \\
\hline 5.661 & 7 & 5.394 & 4.496 & 8 & 7.761 \\
\hline 7.126 & 8 & 4.897 & 5.661 & 9 & 6.935 \\
\hline 8.972 & 13 & 6.321 & 7.126 & 4 & 2.448 \\
\hline 11.295 & 12 & 4.635 & 8.972 & 7 & 3.404 \\
\hline 14.219 & 11 & 3.375 & 11.295 & 8 & 3.090 \\
\hline 17.901 & 6 & 1.462 & 14.219 & 5 & 1.534 \\
\hline 22.536 & 10 & 1.936 & 17.901 & 5 & 1.218 \\
\hline 28.371 & 7 & 1.076 & 22.536 & 8 & 1.549 \\
\hline 35.717 & 12 & 1.466 & 28.371 & 6 & 0.923 \\
\hline 44.965 & (j) & 0.582 & 35.717 & 6 & 0.733 \\
\hline 56.607 & 9 & 0.694 & 44.965 & 5 & 0.485 \\
\hline 71.264 & 3 & 0.184 & 56.607 & 5 & 0.385 \\
\hline \multirow[t]{2}{*}{89.716} & 7 & 0.340 & 71.264 & 3 & 0.184 \\
\hline & & & 89.716 & 3 & 0.146 \\
\hline \multicolumn{3}{|c|}{ (3) Jong Beach 1933} & \multirow[b]{2}{*}{ (6) San } & \multirow{2}{*}{\multicolumn{2}{|c|}{ Francisco 1957}} \\
\hline 1.129 & 3 & 11.586 & & & \\
\hline 1.422 & 1 & 3.068 & 1.129 & 7 & 27.034 \\
\hline 1.790 & 2 & 4.874 & 1.422 & 9 & 27.611 \\
\hline 2.254 & 3 & 5.807 & 1.790 & 2 & 4.874 \\
\hline
\end{tabular}


'Table 11 - Continued

\begin{tabular}{|c|c|c|c|c|c|}
\hline$l_{l}$ & $N_{i}$ & $n_{i}$ & $t_{i}$ & $M_{i}$ & $n_{i}$ \\
\hline 2.254 & (i) & 11.614 & \multirow{2}{*}{\multicolumn{3}{|c|}{ (9) Chalkidike 1932}} \\
\hline 2.837 & 2 & 3.075 & & & \\
\hline 3.572 & 5 & 6.107 & 1.790 & $\begin{array}{l}6 \\
4\end{array}$ & $\begin{array}{r}1+.621 \\
7.7+3\end{array}$ \\
\hline 4.496 & (;) & 5.821 & $\begin{array}{l}2.254 \\
2.837\end{array}$ & + & $(0.150$ \\
\hline 5.661 & $?$ & $1.5+1$ & $\begin{array}{l}2.837 \\
3.572\end{array}$ & 12 & 14.656 \\
\hline $\begin{array}{l}7.126 \\
8.972\end{array}$ & $\frac{2}{3}$ & $\begin{array}{l}1.224 \\
1.459\end{array}$ & $\begin{array}{l}3.962 \\
4.496\end{array}$ & 9 & 8.731 \\
\hline 11.295 & 2 & 0.772 & 5.661 & (j) & 4. 624 \\
\hline 14.219 & 2 & 0.614 & 7.126 & ij & 3.673 \\
\hline 17.901 & 6j & 1.462 & 8.972 & (i) & 2.917 \\
\hline 22.536 & 5 & 0.968 & 11.295 & (j) & 2.317 \\
\hline 28.371 & 3 & 0.451 & 14.219 & 8 & 2.454 \\
\hline 35.717 & 3 & $0.366 j$ & 17.901 & 4 & 0.975 \\
\hline+4.965 & 4 & 0.388 & $22.536 \mathrm{j}$ & 1 & 0.194 \\
\hline 56.607 & 4 & 0.308 & 28.371 & 1 & 0.154 \\
\hline 71.264 & 1 & 0.061 & 35.717 & 2 & 0.244 \\
\hline \multirow[t]{4}{*}{89.716} & i) & 0.292 & $4+.965$ & $\overline{1}$ & 0.0997 \\
\hline & & & 56.607 & 2 & 0.154 \\
\hline & & & 71.264 & 1 & 0.061 \\
\hline & (7) Salinas 1 & 1963 & 89.716 & + & 0.195 \\
\hline 1.292 & 3 & 5.129 & \multirow{2}{*}{\multicolumn{2}{|c|}{ (I0) Western Thessaly }} & \\
\hline 2.048 & 2 & 2.158 & & & 1954 \\
\hline 3.246 & 4 & 2.723 & 1.292 & 13 & 22.226 \\
\hline $5.1+5$ & 6 & 2.577 & 2.048 & 9 & 9.709 \\
\hline 8.155 & 3 & 0.813 & 3.246 & 13 & $8.8+9$ \\
\hline 12.924 & 8 & I. 368 & $5.1+5$ & 24 & 10.307 \\
\hline \multirow[t]{4}{*}{20.484} & 2 & 0.216 & 8.155 & 32 & 8.671 \\
\hline & & & 12.924 & 20 & $3 .+19$ \\
\hline & & & $20 .+84$ & 11 & 1.187 \\
\hline & (8) Parkfield & 1966 & $32 .+(35)$ & 34 & 2.314 \\
\hline & & & $51 .+53$ & 26 & 1.117 \\
\hline 1.129 & 4 & $15 .+48$ & 81.548 & 7 & 0.190 \\
\hline 1.422 & 7 & 21.475 & & & \\
\hline 1.790 & 5 & 12.184 & \multirow{2}{*}{\multicolumn{3}{|c|}{ (11) Amorgos 1956 }} \\
\hline 2.254 & 10 & 19.356 & & & \\
\hline 2.837 & 2 & 3.075 & & & \\
\hline 3.572 & 4 & 4.885 & 1.129 & 27 & 104.275 \\
\hline 4.496 & 9 & 8.731 & 1.422 & 27 & 82.832 \\
\hline $5.6(i)$ & 5 & 3.853 & 1.790 & 26 & 63.358 \\
\hline 7.126 & 3 & 1.836 & 2.254 & 24 & 46.455 \\
\hline 8.972 & 3 & 1.459 & 2.837 & 6 & 9.225 \\
\hline 11.295 & 3 & 1.159 & 3.572 & 12 & 14.656 \\
\hline 14.219 & 5 & 1.534 & 4.496 & 13 & 12.612 \\
\hline 17.901 & 6 & 1.462 & 5.6611 & 5 & 3.853 \\
\hline 22.536 & 5 & 0.968 & 7.126 & 10 & 6.121 \\
\hline 28.371 & 9 & 1.334 & 8.972 & 4 & 1.945 \\
\hline 35.717 & 10 & 1.221 & & & \\
\hline$+4.9(65)$ & 5 & 0.485 & $(12)$ & Marnesia 1957 & \\
\hline 56.607 & 4 & 0.308 & & & \\
\hline 71.264 & 4 & 0.245 & 1.292 & 13 & 22.226 \\
\hline 89.716 & $\pi$ & $0.2+3$ & 2.048 & + & 4.315 \\
\hline
\end{tabular}


Table 11 - Continued

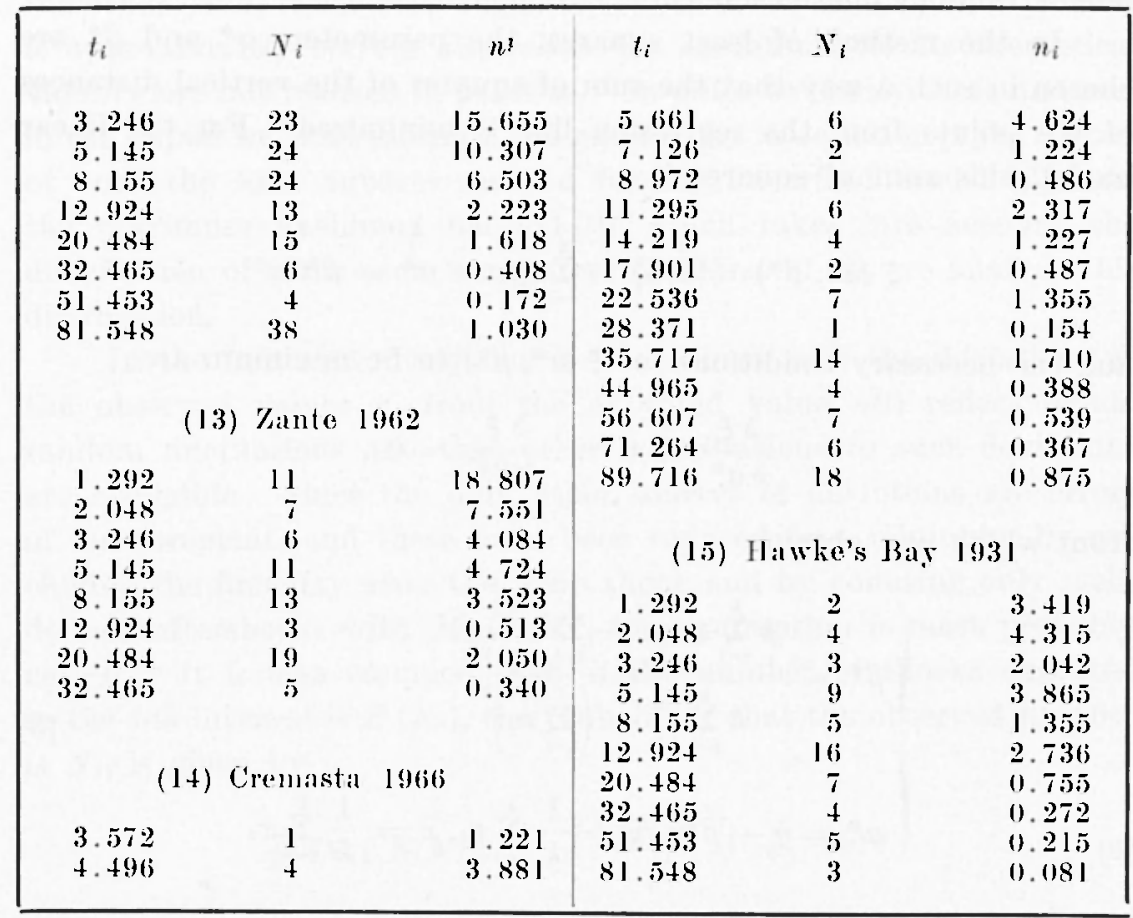

that is, Omori's law. The commonest procedure for estimating the parameters $a$ and $\beta$ is the least squares method, which has been applied to the great majority of aftershock sequences whose time distribution has been investigated so far. Accordingly, relation [1] is linearized by taking logarithms on both sides

$$
\log n(t) \quad \ldots \log \alpha-\beta \log t .
$$

Then, settingr

$$
\log n(t)=y, \log t=x, \log \alpha=\alpha^{*},-\beta=\beta^{*}
$$

the following model is obtained

$$
y=\alpha^{*}+\dot{\beta}_{x}^{*}
$$

that is, the expected value of $y$ is a linear function of $x$. Therefore

$$
y_{i}=\alpha^{*}+\beta^{*} x_{i},+\varepsilon_{i}
$$


i.e., the observation $y_{1}$ consists of the expected value at the given $a_{i}$ plus a random fluctuation $\varepsilon_{i}$.

In the method of least squares, the parameters $\alpha^{*}$ and $\rho^{*}$ are chosen in such a way that the sum of squares of the vertical distances of the points from the regression line is minimized. For the linear model, this sum of squares is

$$
\xi\left(\alpha^{*}, \beta^{*}\right)=\sum_{i=1}^{i} \varepsilon_{i}^{*}=\sum_{i=1}^{k}\left(y_{i}-\alpha^{*}-\beta^{*} x_{i}\right)^{*}
$$

and the necessary conditions for $\xi\left(\alpha^{*}, \beta^{*}\right)$ to be minimum are

$$
\frac{\partial \xi}{\partial \alpha^{*}}=0 \quad, \quad \frac{\partial \xi}{\partial \beta^{*}}=0
$$

from which one obtains

$$
\left\{\begin{array}{l}
\beta^{*}=\frac{k \sum_{i=1}^{k} x_{i} y_{i}--\sum_{i=1}^{k} x_{i} \sum_{i=1}^{k} y_{i}}{l i \sum_{i=1}^{k} x_{i}^{*} \cdots\left(\sum_{i=1}^{k} x_{i}\right)^{2}} \\
a^{*}=y-p^{n} \bar{x}, \bar{y}=\frac{1}{k} \sum_{i=1}^{k} y_{i}, \bar{x}=\frac{1}{k} \sum_{i=1}^{k} x_{i}
\end{array}\right.
$$

Arcording to the Ganss-Markov theorem $\left({ }^{22}\right)$, the estimates of the parameters calculated acording to the least squares method will be unbiased and of maximum efficiency if, and only if, the linear hypothesis is such that the random fluctuation $\varepsilon$ has zero mean and constant variance (independent of $x$ ). In other words, if the calculated regression line is to give the expected value of $y$ for each $x$, the observed values must be uncorrelated, and the probability distribution of $y$ for each $x$ must be symmetric. In many cases, especially when the fluctuation $\varepsilon$ can be considered to be the sum of many independent factors, the conditions of the Gauss-Markov theorem are satisfied and the probability distribution of $y$ may be regarded as approximately normal for every $x$. In other cases, however, the matter is very debatable, particularly when a transformation of coordinates is performed in order to linearize the least square model.

It turns out that, under reasonable assumptions, neither the original model [1] nor the linearized model [2] satisfy the conditions of the Gauss-Markov theorem. This has been noted, for instance, by Page $\left({ }^{3}\right)$. An appropriate method must take into account the prob- 
ability distribution of $n$ for each interval of time considered. On the other hand, it has been suggested (-3) that, the least squares method is approximately correct also when the conditions for its theoretical validity are not realized in practice. In order to clarify these matters, in the sequel we shall estimate the parameters in equation [1] by means of both the least squares method for the linearized model [2], and the maximum likelihood method $\left({ }^{24}\right)$, which takes into accomnt the distribution of $n$ for each time interval. First of all, we analyze this distribution.

In the following discussion it is assumed that the deviations of the observed values $n_{i}$ from the expected value $n(t)$ reflect actual random fluctuations and that other contributions to such deviations are negligible. Since the only other sources of deviations are errors of measurement, and these have been reduced to a minimum by excluding the first day after the main shock and by counting only welldefined aftershocks with $M \geqslant M^{*}$, the assumption is most probably correct. It is also assumed that, if the number of shocks expected in the $i$-th interval is $E\left(N_{i}\right)$, the probability that the observed number is $N_{i}$, is griven by

$$
p\left(N_{i} ; E\left(N_{i}\right)\right)=\frac{\left[E\left(N_{i}\right)\right]^{N_{i}}}{N_{i} !} e^{-E\left(N_{i}\right)}
$$

i.e., the number of shocks in each time interval is given by a Poisson distribution. The Poisson distribution is the most fundamental distribution for such discrete variates as the number of shocks in a given time interval, and it has been postulated for the case of aftershocks by a number of authors, e.g., recently, by Utsu ( $\left.{ }^{21}\right)$ and Page $\left(^{3}\right)$.

The expected value $E\left(N_{i}\right)$ in the $i$-th interval is given by

$$
E\left(N_{i}\right)=\int_{l_{i}}^{t_{i+1}^{*}} n(t) d t=\int_{t_{i}^{\pi}}^{t_{i+1}^{*}} a t^{-\beta} d t \simeq \alpha t_{i}^{-\beta} \Delta t_{i}^{*}
$$

where the approximation is introduced in order to avoid using the integral in equation [4]; this is necessary because $B$ is unknown and could be unity. The approximation has been checked numerically for some randomly selected samples and the error was found to be negligible. Then relation [t] becomes

$$
p\left(N_{i} ; \alpha, \beta\right)=\frac{\left(\alpha t_{i}^{-\beta} \Delta t_{i}^{*}\right)^{N_{i}}}{N_{i} !} e^{-\alpha t_{i}-\beta} \Delta t_{i}^{*}
$$


The principle of the method of maximmm likelihood is to take estimates of the mnknown parmeters that maximize the probability of obtaining the observed sample. Considering a sample of $k$ independent. values, each with a probability distribution $p\left(N_{i}: \alpha, \beta\right)$, the probability that the sample consists precisely of these $k$ values is

$$
L(\iota, \beta)=\prod_{i=1}^{k} p\left(N_{i} ; \iota, \beta\right)
$$

The function $L(\alpha, \beta)$ is called the likelihood function. The necessary condition for $L(\alpha, \beta)$ to have a maximum is

$$
\frac{\partial L}{\partial \alpha}=0 \quad, \quad \frac{\partial L}{\partial \beta}=0 \text {. }
$$

Since ln $L(\alpha, \beta)$ (where ln stands for the natulal logarithm) attains its maximum for the same values of a and $\beta$ as $L(\alpha, \beta)$ itself, it is the function ln $L(\alpha, \beta)$ which is commonly maximized. It follows from equations $[6]$ and $[7]$ that the likelibood function in the present problem is

$$
L(\alpha, \beta)=\prod_{i=1}^{k} \frac{\left(\alpha t_{i}^{-\beta} \Delta t_{i}^{*}\right)^{N_{i}}}{N_{i} !} e^{-\alpha t_{i}^{-\beta} \Delta t_{i}^{*}}
$$

i.e.,

$$
\ln L(\alpha, \beta)=\sum_{i=1}^{k} \ln \left|\frac{\left.\alpha t_{i}^{-\beta} \Delta t_{i}^{*}\right)^{N_{i}}}{\tilde{N}_{i} !} e^{-\alpha t_{i}^{-\beta} \Delta t_{i}^{*}}\right|
$$

from which one obtains

$$
\begin{aligned}
& \ln L(\alpha, \beta)=\ln \alpha \sum_{i=1}^{k} N_{i}-\beta \sum_{i=1}^{k} N_{i} \ln t_{i}+\sum_{i=1}^{k} N_{i} \ln \Delta t_{i}^{*}- \\
& -\| \sum_{i=1}^{k} t_{i}^{-\beta} \Delta t_{i}^{*}-\sum_{i=1}^{k} \ln N_{i} \text { ! }
\end{aligned}
$$

The maximum likelihood estimates of $\alpha$ and $\beta$ are obtained by solving the equations

$$
\left\{\begin{array}{l}
\frac{\partial \ln L(\alpha, \beta)}{\partial \alpha}-\frac{1}{\alpha} \sum_{i=1}^{k} N_{i}-\sum_{i=1}^{k} t^{-\beta} \Delta t^{*}-0 \\
\frac{\partial \ln L(\alpha, \beta)}{\partial \beta}=-\sum_{i=1}^{k} N_{i} \ln t_{i}+\alpha \sum_{i=1}^{k} t_{i}^{-\beta} \Delta t_{i}^{*} \ln t_{i}=0
\end{array}\right.
$$


i.e.,

$$
\begin{aligned}
& \sum_{i=1}^{k} N_{i}-\alpha \sum_{i=1}^{k} t_{i}^{-\beta} \Delta t_{i}^{*}=0 \\
& \mid \sum_{i=1}^{k} N_{i} \ln t_{i}-\alpha \sum_{i=1}^{i} t_{i}^{\prime} \Delta t_{i}^{*} \ln t_{i}=0
\end{aligned}
$$

Equations [8] are the normal equations in the maximum likelihood method. From then one obtains,

$$
\alpha=\frac{\sum_{i=1}^{k} N_{i}}{\sum_{i=1}^{k} t_{i}^{-P^{\prime}} \Lambda t_{i}^{*}}=\frac{\sum_{i=1}^{k} N_{i} \ln t_{i}}{\sum_{i=1}^{k} t_{i}^{-\beta} \Delta t_{i}^{*} \ln t_{i}}
$$

i.e.,

$$
F(\beta)=\sum_{i=1}^{k} N_{i} \sum_{i=1}^{k} t_{i}^{-\beta} \Delta t_{i}^{*} \ln t_{i}-\sum_{i=1}^{k} N_{i} \ln t_{i} \sum_{i=1}^{k} t_{i}^{-\beta} \Delta t_{i}^{*}=0 .
$$

Equation [10] must be solved for $\beta$, and then $\alpha$ can be obtained from [9].

A program has been written to solve equation [10] by the secant method (25). The first approximation to the root of [10] and to the estimate of $a$ has been obtained by means of the least squares method for the linearized model, according to formulas [3]. The estimates $a_{1}, \beta_{1}$ obtained by the least squares method, when compared with the maximum likelihood estimates, give an idea on how statistically reliable the least squares method is when the underlying assumptions are not met.

The numerical results for the 15 sequences are summarized in Table III. From left to right, the columms indicate the sequence involved, the least square estimates $\alpha_{1}, \underset{p}{\beta}$, and the maximum likelihood estimates $\alpha, \beta$. The parameter which characterizes a sequence is the decay parameter $\beta$, which measures the rate of decay in time of the frequency of aftershocks. It can be seen that differences between $\beta_{1}$ and $\beta$ are present but not very large. The decay parameter is usually around unity.

Now, we proceed to check the validity of the time-frequency law. If the expected value of the frequency $n$ varies in time according to equation [1], and using the approximation expressed by [5], the mean and the variance of the Poisson-distributed number of shocks are in each interval

$$
E(N)=V(N)=n(t) \Delta t^{*}=a t^{-\beta} \Delta t^{*}
$$


and therefore the standard deviation of $n$ is

$$
I(u)=\sqrt{\frac{\alpha t^{--\beta}}{2 t * *}} .
$$

Table III Fetimates of THE PARAMETERS IS THE TIME-FIEQUENCY LAW

\begin{tabular}{|c|c|c|c|c|c|}
\hline \multirow{2}{*}{\multicolumn{2}{|c|}{ sequence }} & \multicolumn{2}{|c|}{ Least square estimates } & \multicolumn{2}{|c|}{$\begin{array}{c}\text { Maximum likelihood } \\
\text { estimates }\end{array}$} \\
\hline & & $a_{1}$ & $\beta_{1}$ & $a$ & $\beta$ \\
\hline (1): & Alaska & 76.824 & 1.097 & 77.547 & 1.085 \\
\hline (2) & Aloutian $\mathrm{I}$. & 32.611 & 0.997 & 33.662 & 0.984 \\
\hline (3) I & Longr Beach & 10.956 & I. 302 & 11.731 & 1.301 \\
\hline (4) 1 & 1)erert llot sip. & 9.303 & 1.075 & 9.970 & $1.0+2$ \\
\hline (5) 1 & Kern County & 36.484 & 1.150 & 39.047 & 1.154 \\
\hline (6) 5 & San Francisco & 19.070 & 1.103 & 22.720 & 1.120 \\
\hline (7) & Salinas & 6.651 & 0.902 & 6.778 & 0.844 \\
\hline (8) 1 & Parkfield & 20.622 & 0.981 & 23.424 & 0.998 \\
\hline (9) & Chalkidiks & 47.918 & 1.448 & 45.392 & 1.355 \\
\hline$(10)$ & WV. 'Thessaly & 32.600 & 0.949 & 34.211 & 0.917 \\
\hline$(11)$ & Amolgos & 150.139 & 1.882 & 151.694 & 1.830 \\
\hline (12): & Ma gruesia & 27.607 & 0.988 & 29.761 & 0.918 \\
\hline$(13) 7$ & Zante & 20.176 & 1.063 & 19.565 & 0.970 \\
\hline$(1+)$ & Cremasta & 4.210 & 0.518 & +.738 & $0 .+81$ \\
\hline$(15) 1$ & llawke's Bay & 8.639 & 0.907 & 11.135 & $0.9+1$ \\
\hline
\end{tabular}

I general theorem which holds for an arbitrary distribution with a second moment is Tchebychev's theorem (24). It states that, if $X$ is a random variable with mean $E(X)$ and standard deviation $D(X)$, then the following inequality holds

$$
P\{|X-E(X)| \geqslant k D(X)\} \leqslant \frac{1}{k^{2}}
$$

where $k$ is an arbitrary positive number. In other words, the probability that $X$ assumes values outside the interval $E(X) \pm k D(X)$ is less than $1 / k=$. Conversely, from the viewpoint of sampling, in the 
long run less than $(100 ; \%) \%$ of the values assumed by $\mathrm{X}$ will fall outsicle the interval.

The application of Thehelychev's inequality to check the validity of the time-frequency law has two limits, namely, it yields rather weak conditions, and the sample size is small. Tevertheless it gives a reasonably safe criterion for rejecting the validity of the law for sequences that show too wide fluctuations. Regarding the observed values of $n$ as the result of random sampling from a population whose expected value varies with time according to [1], and choosing $k=\mathbf{2}$, Thebychev's inequality takes the form

$$
P\left\{\left|n-\alpha t^{-\beta}\right| \geqslant 2 \mid \sqrt{\frac{\alpha t^{-\beta}}{\Delta t^{*}}}\right\} \leqslant \frac{1}{4}
$$

that is, in the long run less than $25 \%$ of the observed values $n_{i}$ should fall outside the interval $E(n) \pm 2 D(n)$. If this condition is not satislied, the assmmption regarding the variation with time of the expected value $n(t)$ must be rejected.

In order to determine a confidence band according to Trhebychev's inequality, therefore, the quantities $E(n)+2 D(n), E(n)-2 D(n)$ have been computed at, selected $t_{i}, i=1,2, \ldots, k$, and compared with the observed $n_{i}$. Table IV gives the results, showing in the columms from left to right the sequence, the total number of data points, the number of points outside the conlidence band, and their percentage. Consequently, according to the selected criterion, sequences (10), (12), (13) and (14) do not follow the assumed timefrequency law, inasmuch as the observed frequency cannot be explained only in terms of random fluctuations from the law. The other 11 sequences appear to follow the law and the fit is generally fairly good. All the sequences which show considerable departures from the assumed law have occurred in the region of Greece; this fact night have some geotectonic significance. However, there exists the possibility that relatively poor instrumentation plays a part in some apparent irregularities. Sequence (14) originated under peculiar conditions; the frequency of aftershocks in it appears to be correlated to the variations in the water loading of a nearby artificial lake ( $\left.{ }^{12}\right)$.

Figures 1 to 5 display on doubly logarithmic paper the results for some of the 11 sequences which appear to decay according to the postulated law. The dots represent the data points, the full line the fitted $n(t)$, and the broken lines the confidence limits. 


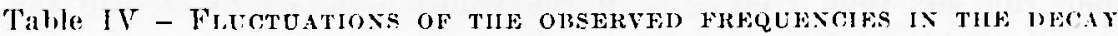
OF AFTEKSHOCK ACTVITY WITI TIME.

\begin{tabular}{|c|c|c|c|c|}
\hline & Sequence & $\begin{array}{l}\text { Total number } \\
\text { of points }\end{array}$ & $\begin{array}{l}\text { Points ontside } \\
\text { confidence band }\end{array}$ & $\begin{array}{l}\text { \% Points } \\
\text { ontside }\end{array}$ \\
\hline (I) & Mlaska & 20 & 2 & $10 \%$ \\
\hline (2) & Alentian 1 & 20 & 0 & - \\
\hline (3) & Iongr Beach & 13 & 0 & - \\
\hline (4) & Desert Hot Sp. & 10 & 0 & - \\
\hline (5) & Kern lounty & 20 & 0 & - \\
\hline (6) & San Francisco & 20 & 0 & - \\
\hline (7) & Salinas & 7 & 0 & - \\
\hline (8) & Parkfield & 20 & 0 & - \\
\hline (9) & Chalkidlike & 18 & 1 & $5.6 \%$ \\
\hline ( 10$)$ & W. Thessaly & 10 & 3 & $30 \quad \%$ \\
\hline (II) & Amorgos & 10 & 1 & $10 \%$ \\
\hline (12) & Magnesia & 10 & 7 & 70 \\
\hline ( 13$)$ & Yante & 8 & 2 & $25 \%$ \\
\hline (14) & Cremasta & 15 & 4 & $26.7 \%$ \\
\hline ( 15$)$ & Hawke's Bay & 10 & 1 & $10 \%$ \\
\hline
\end{tabular}

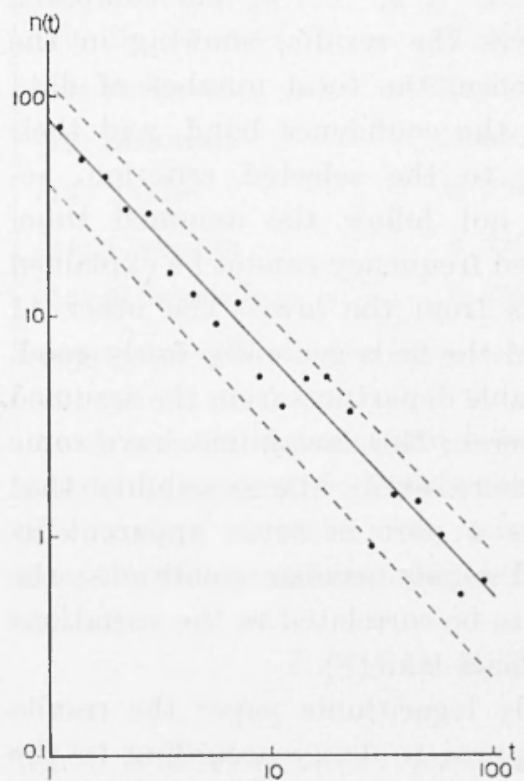

Fig. 1. - Time distribution of aftershocks: Alaska 1964.

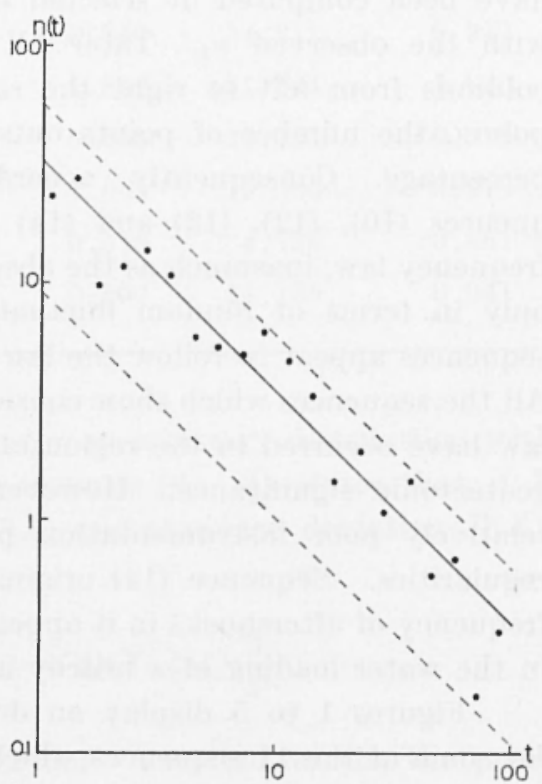

Fig. 2. - Time distribution of aftershocks: Aleutian Islands 1957. 


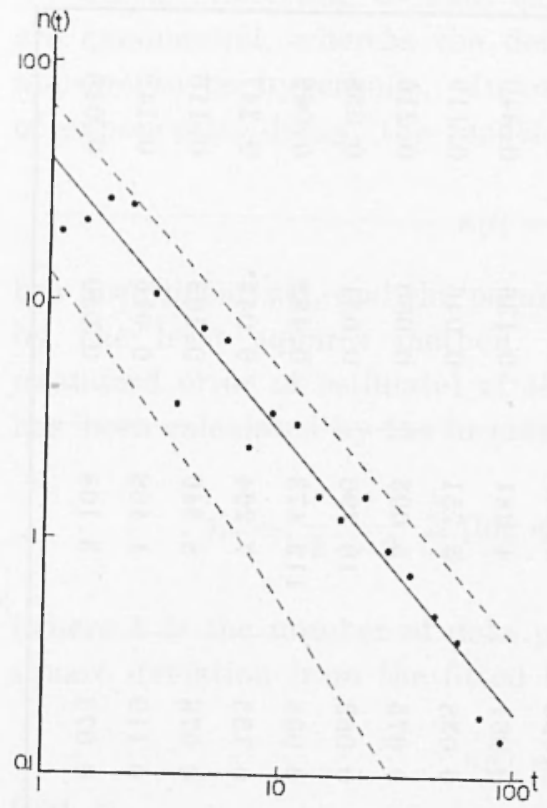

Fig. 3. - Time distribution of aftershocks: Kern County 1952.

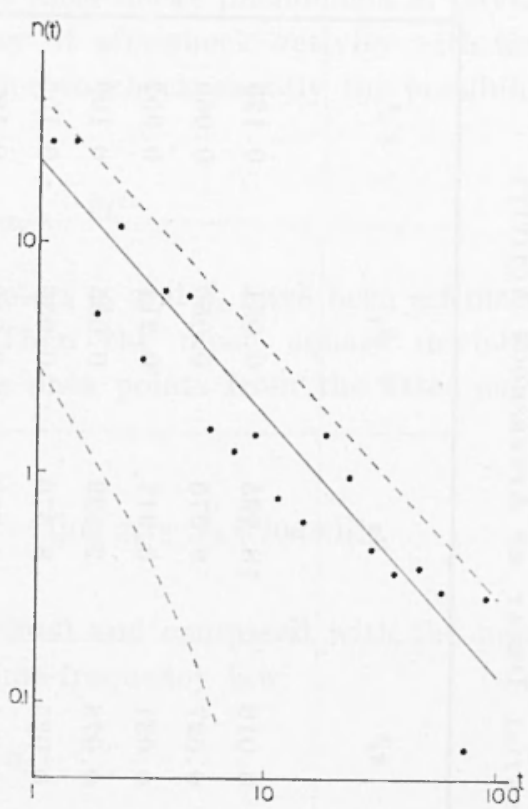

Iig. 4. - Time distribution of aftershocks: San Francisen 1957.

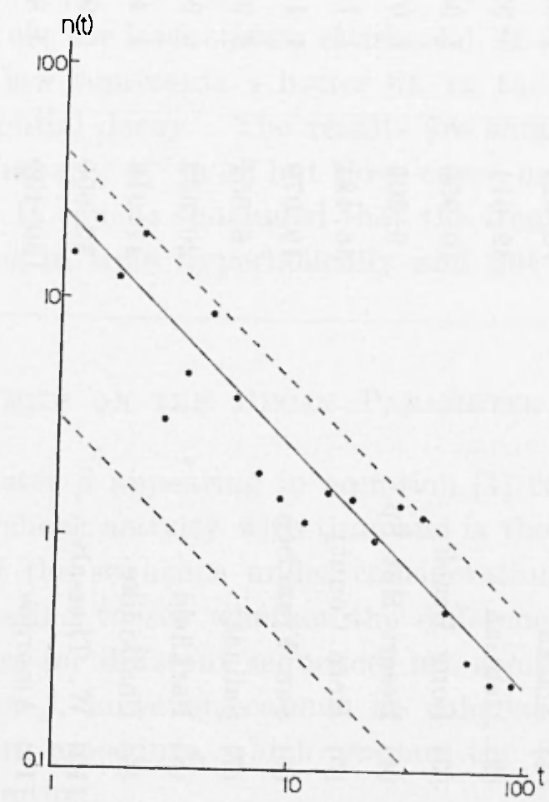

Fig. 5. - Time distribution of aftershocks: Parkfield 1966. 
Table $V$ - Comparisox of Hyperbolic and Exponextha Decay of Artersiock ACtivity.

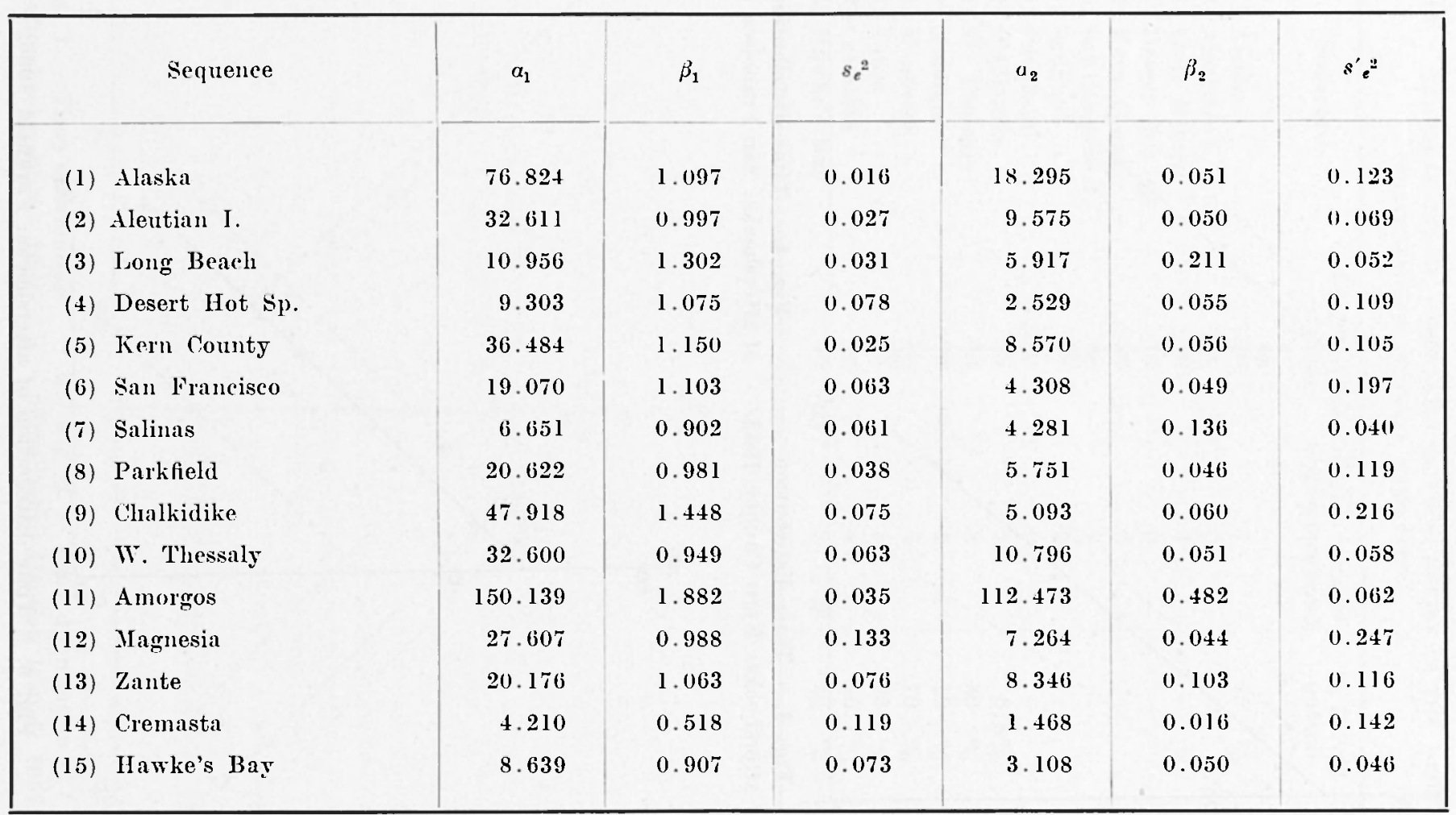


Its is interesting to note that most decay phenomena in physics are exponential, whereas the decay of aftershock activity with time appears to be hyperbolic. In order to check rapidly the possibility of exponential decay, the model

$$
n(t)=a_{2} e^{-\beta_{2} t}
$$

has been linearized, and the parameters $\alpha_{2}$ and $\beta_{2}$ have been estimated by the least squares method. Then the mean square deviation (standard error of estimate) of the data points from the fitted curve las been calculated by the formula

$$
s_{e}=\frac{1}{l-2} \sum_{i=1}^{k}\left[\log n_{i}-\left(\log \alpha_{2}-\beta_{2} t_{i} \log e\right)\right]^{2}
$$

(where $k$ is the number of data points) and compared with the mean square deviation from the fitted time-frequency law

$$
\eta(t)=\alpha_{1} t-\beta_{1}
$$

that is,

$$
s_{e}^{2}=\frac{1}{k-2} \sum_{i=1}^{k}\left[\log n_{i}-\left(\log \alpha_{1}-\beta_{1} \log t_{i}\right)\right]^{2}
$$

(where $\alpha_{1}$ and $B$, are the least square estimates). If $s_{e}^{2}<s_{e}^{\prime \prime \prime}$ the assumed time-frequency law represents a better fit, in the least square sense, than the exponential decay. The results are summarized in Table $V$. It can be seen that $s_{e}^{2}<s_{e}^{\prime \prime}$ in all but three cases, namely, sequences ( $\overline{)}$, (10), and (15). It can be concluded that the frequency of aftershocks usually decreases in time lyyperbolically and not exponentially.

\section{Confunexce Lames ox the Dechy PARAMelels.}

The parameter $\beta$ appearing in equation [1] is related to the rate of decay of aftershock activity with time and is therefore an important characteristic of the sequence under consideration. Consequently, it would be interesting to see whether the differences in the computed decay parameters for dillerent sequences are significant or not. Confidence limits on $\beta$, however, cannot be calculated according to the usual least square procedure, which assumes the fluctuations to have a normal distribution. 
An approximate procedure for calculating confidence limits on $\beta$ can be based on the addition theorem for the Poisson distribution $\left(^{-4}\right)$. Since in this procedure the parameter $\alpha$ is assumed to be known exactly, it will yield no more than an indication of the range in which the real value of $\beta$ is likely to fall.

The addition theorem for the Poisson distribution states that, if $N_{i}, i=1,2, \ldots, k$, is a sequence of stochastically independent and Poisson-distributed random variables with expected values $E_{i}=$ $E\left(N_{i}\right)$, then the sum $I=\sum_{i=1}^{k} N_{i}$ will be Poisson-distributed with expected value $E(X)=\sum_{i=1}^{k} E_{i}$. In the present case, $X_{i}$ being the number of shocks in the $i$-th time interval, the expected values are

$$
E_{i}=\alpha t_{t}^{-\beta} \Delta t^{*}
$$

and

$$
\boldsymbol{H}(X)=\alpha \sum_{i=1}^{k} t_{i}^{i} \Delta t_{i}^{*} .
$$

The value of $E(X)$ for each of the 11 sequences which follow the time-frequency law is such that the distribution of $I$ can be approximated by the normal distribution. Therefore the standardized variable

$$
I^{*}=\frac{X-E(X)}{D(X)}
$$

is approximately normally distributed with $E\left(X^{*}\right)=0, \quad V\left(X^{*}\right)=1$. Therefore, the probability that $X^{*}$ assumes a value in the interval $\left(\lambda_{1}, \lambda_{2}\right)$ is

$$
I^{\prime}\left\{\lambda_{1} \leqslant X^{*} \leqslant \lambda_{2}\right\}=\Phi\left(\lambda_{2}\right)-\Phi\left(\lambda_{1}\right)
$$

where $\Phi\left(I^{*}\right)$ is the normal distribution function. In particular

$$
I^{\prime}\left\{-1.96 \leqslant I^{*} \leqslant 1.96\right\}=0.95
$$

Then the apploximate $95 \%$ confidence limits on the decay parameter are obtinined by solving for $\beta$ the equations

$$
I^{*}= \pm 1.96
$$

that is, recalling the definition of $X *$ 


$$
\frac{\sum_{i=1}^{k} N_{i}-\alpha \sum_{i=1}^{k} t_{i}^{-\beta} \Delta t_{i}^{*}}{\sqrt{a \sum_{i=1}^{k} t_{i}^{-\beta} \Delta t_{i}^{*}}}= \pm 1.96
$$

Naturally, the central value of $X^{*}$ is obtained when $\alpha, \beta$ are given by the maximum likelihood estimates. Assuming the value of $a$ to be known exactly, the above equations take the form

$$
\left\{\begin{array}{l}
\sum_{i=1}^{k} N_{i}-\alpha \sum_{i=1}^{k} t_{i}^{-\beta} \Delta t_{i}^{*}-1.96 \sqrt{\alpha \sum_{i=1}^{k} t_{i}^{-\beta} \Delta t_{i}^{*}=0}=0 \\
\sum_{i=1}^{k} N_{i}-\alpha \sum_{i=1}^{k} t_{i}^{-\beta} \Delta t_{i}^{*}+1.96 \sqrt{\alpha \sum_{i=1}^{k} t_{i}^{-\beta} \Delta t_{i}^{*}}=0 .
\end{array}\right.
$$

liquations [1.1] have been solved by the secant method. The results for the 11 sequences with time-frequency law of the form given by [1] are shown in Table VI. It can be seen that the $95 \%$ confidence limits on the maximum likelihood estimate always contain the least square estimate of $\beta$, which therefore appears to be a good approximation to the real value of the decay parameter.

Table VI - CoNfiderce himits ox THE DeCay PARAMETEL.

\begin{tabular}{|l|l|}
\hline \multicolumn{1}{|c|}{ Sequences } & $95 \%$ Conficlence limits \\
\hline (1) Alaska & $1.033 \leqslant \beta \leqslant 1.139$ \\
(2) Alentian I. & $0.920 \leqslant \beta \leqslant 1.052$ \\
(3) Long Beach & $1.009 \leqslant \beta \leqslant 1.650$ \\
(4) Desert Hot sp. & $0.913 \leqslant \beta \leqslant 1.185$ \\
(5) Kern County & $1.072 \leqslant \beta<1.242$ \\
(6) San Franciseo & $1.020 \leqslant \beta \leqslant 1.229$ \\
(7) Salinas & $0.645 \leqslant \beta \leqslant 1.064$ \\
(8) Parkficld & $0.919 \leqslant \beta \leqslant 1.082$ \\
(9) Chalkidike & $1.254 \leqslant \beta \leqslant 1.464$ \\
(11) Anorgos & $1.644 \leqslant \beta \leqslant 2.032$ \\
(15) Hawke's Bay & $0.829 \leqslant \beta \leqslant 1.051$ \\
\hline
\end{tabular}


The values listed in Table VI must not be considered as exact. The limits rounded to the second decimal digit are probably fairly reliable. Most $\beta$-values cluster around the 0.9-1.2 range. Sequence (11) stands by itself, showing a very rapid decay in activity. Also sequence (9) has a decay coefficient somewhat higher than usual. This fact hintis at the possibility that sequences in Greece decay more rapidly; but no conclusion can be reached with such a small sample size.

\section{Magnitude Stabihtix ix Time.}

When the characteristics of aftershock sequences with respect to magnitude are examined, two sources of error are added to the possibility of the incompleteness of data; namely, lack of accuracy in magnitude determination, and confusion between different magnitude scales. Unfortunately, authors sometimes do not specify which scale they are using. When one single sequence is being examined, no problems arise, because the data are consistent within the sequence; if, however, results for different sequences are to be compared, the use of different magnitude scales may affect the conclusions. In the sequel, the various "local" magnitude scales, for the purposes of comparison of results among sequences, have been assimilated to $M$. Thus the only distinction left is between $M$ and $m$; the latter scale lias been used only in sequence (1).

Two aspects of the sequences have been examined in detail. namely, the variation of aftershock magnitudes with time, and the magnitude-frequency distribution. For all sequences except (1), where $1 \leqslant t \leqslant 100$ days, the data for $t \leqslant 100$ days have been included in the analysis. We first consider the distribution of magnitude with respect to time.

The overall mean magnitude, $M$, has been calculated for each sequences as

$$
M=\frac{1}{K} \sum_{i=1}^{K} M_{i} \quad, \quad i=1,2, \ldots, K
$$

where $K$ is the total number of aftershocks in the sequence. Then the mean magnitude, $M^{\prime}$, of each group of 10 successive aftershocks is computed, thereby eliminating large individual fluctuations. In almost all the sequences considered the mean magnitude $M^{\prime}$ oscillates about $M$ during the whole length of the sequence and no appreciable 
decrease with time is detectable for $t \leqslant 100$ days. When a sequence lasts less than 100 days, the mean magnitude is stable throughout the sequence. Sometimes higher values of $M^{\prime}$ are observed in the first few hours after the main shock, but this can almost certainly be attributed to the fact that some shocks with $M \geqslant M^{*}$ are not detected when the frequency is very large. Figure 6 gives an example. The dotted line represents $M$.

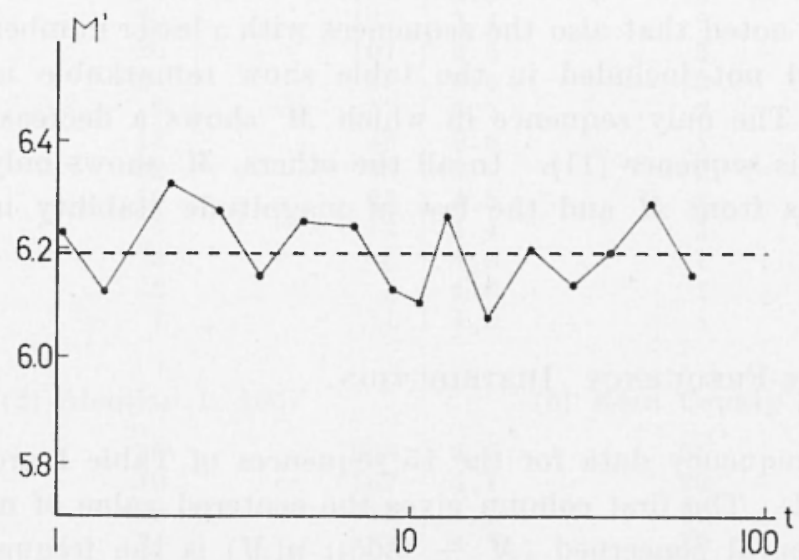

Fig. 6. -- Magnitude stability in time: Aleutin Islands 1957.

Thus, the law of magnitude stability in aftershock sequences (first proposed by Lomnitz ( $\left.{ }^{2-1}\right)$ ) is fully confirmed; during an aftershock sequence the mean magnitude of the shocks is constant in time.

Table VII - Osciclations of Mean Magnitude.

\begin{tabular}{|c|c|c|c|}
\hline Sequence &.$M$ & Number of $M_{i}^{\prime}$ & $\begin{array}{l}\% \text { Within } \\
M \pm 0.20\end{array}$ \\
\hline (1) Mlaska & 4.89 & 29 & $89.7 \%$ \\
\hline (2) Aleutian I. & 6.19 & 20 & $100 \%$ \\
\hline (5) Kern County & 4.44 & 18 & $83.3 \%$ \\
\hline (6) San Francisco & 2.55 & 16 & $81.3 \%$ \\
\hline (8) Parkfield & 2.46 & 17 & $88.2 \%$ \\
\hline (10) W. Thessaly & 3.83 & 29 & $89.7 \%$ \\
\hline (11) Amorgos & 3.9 .2 & 40 & $65.5 \%$ \\
\hline (12) Magnesia & 3.43 & 29 & $72.4 \%$ \\
\hline (13) Zante & 3.87 & 13 & $100 \%$ \\
\hline (14) Cremasta & 3.75 & 10 & $100 \%$ \\
\hline
\end{tabular}


Consequently, the decrease of seismic activity with time is solely due to the decrease in aftershock frequency.

Moreover, the fluctuations of $Y^{\prime}$ about the overall mean magnitude II are not very wide. Table VII summarizes the results for the sequences with a larger number of shocks. From left to right, the first column indicates the sequence, the second the overall mean magnitude, the third the number of calculated $M_{i}^{\prime}$-points, and the fourth the percentage of such points which fall within the interval $M \pm 0.20$. It is to be noted that also the sequences with a lesser number of aftershocks and not included in the table show remarkable magnitude stability. The only sequence in which $M^{\prime}$ shows a decreasing trend with time is sequence (11). In all the others, $M^{\prime}$ shows only random fluctuations from $M$ and the law of magnitude stability in time is satisfied.

\section{Magnitude-Frequenct Distributiox.}

The frequency data for the 15 sequences of Table I are listed in Table VIIT. The first column gives the centered value of magnitude in the interval concerned $(M \pm 0.05) ; n(M)$ is the frequency; and $N(M)$ the cumulative frequency. For brevity, intervals in which the frequency was zero have been omitted from the Table. The magnitudes in sequence (1) are in the $m$-scale. The most commonly accepted form for the magnitude-frequency distribution, in ase of both independent seismic events and aftershock sequences, is

$$
\log n(M)=a-b M
$$

where $\log$ is the logarithm to the base 10 and $n(M I)$ is the number of shocks with $M+d M\left({ }^{15}\right)$.

Equation [12] is to be regarded as expressing a statistical relationship. Usually, the coefficients $a$ and $b$ have been calculated according to the least squares method. Suzuki $\left({ }^{2}\right)$ has pointed out that this is not rigorous, because $\log n(M)$ is not symmetrically distributed with uniform variance for each magnitude interval $\Delta M$.

In this section we shall define $n(M)$ is such a way that $\log n(M)=a$ not when $H=0$, as in equation [12], but when $M=M *$, where $I^{*}$ is the minimum detectable magnitude in the sequence. Then the magnitude-frequency law takes the form

$$
\log u(. H)=a-b\left(M-M^{*}\right) \quad, \quad . M \geqslant M^{*} .
$$


'Table VIII - Magnitude-FREQUENCY DISTRHUTION.

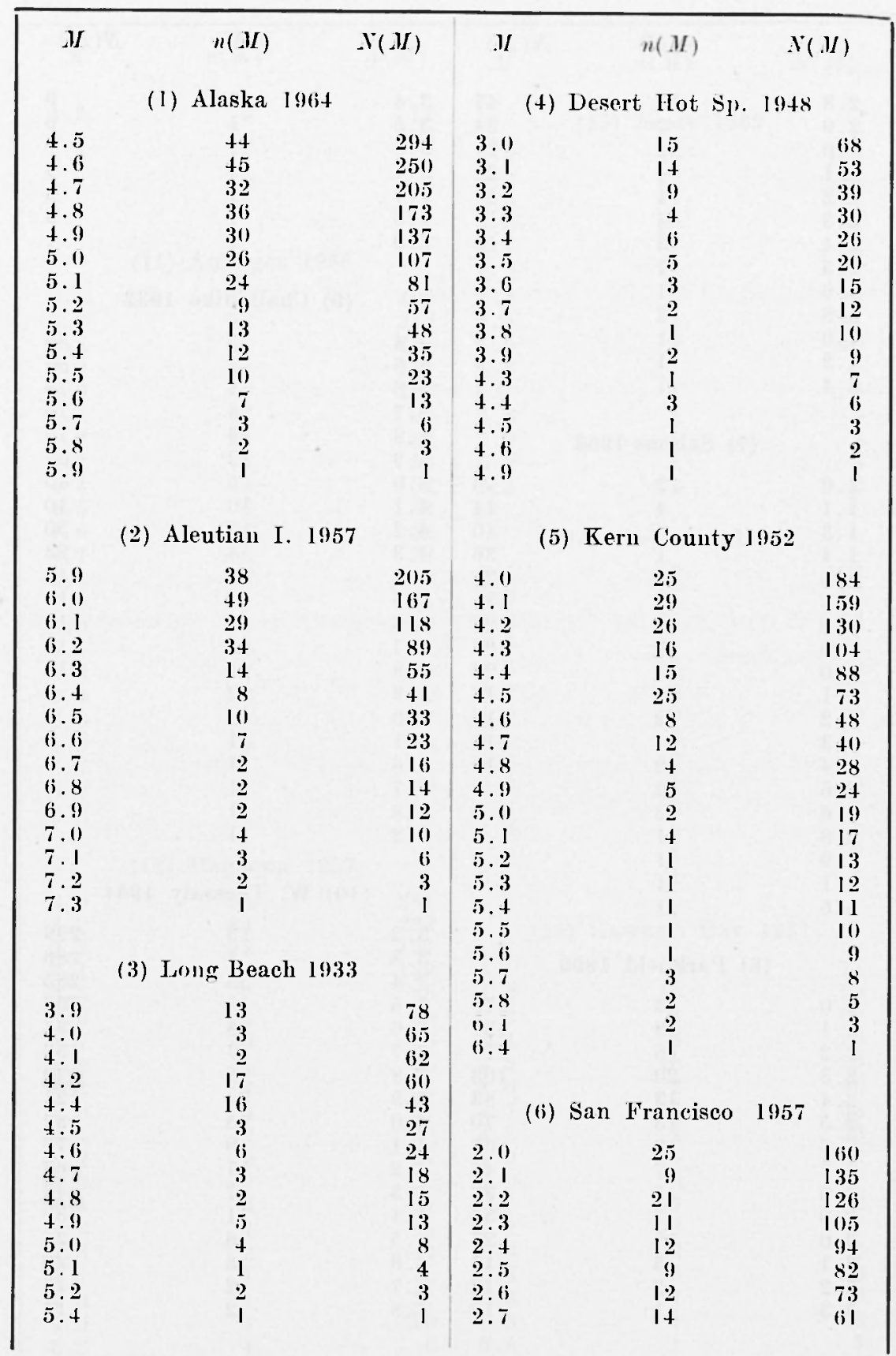


Table VIII - Continuod

\begin{tabular}{|c|c|c|c|c|c|c|}
\hline$M$ & $n(M)$ & $N(M)$ & $M$ & & $n(M)$ & $V(\lambda)$ \\
\hline 2.8 & 13 & 47 & 3.4 & & 3 & 9 \\
\hline 2.9 & 7 & 34 & 3.5 & & 1 & 6 \\
\hline 3.0 & 6 & 27 & 3.6 & & 1 & 5 \\
\hline 3.1 & 4 & 21 & 3.7 & & 1 & 4 \\
\hline 3.2 & 4 & 17 & 4.1 & & 1 & 3 \\
\hline 3.3 & 3 & 13 & 4.5 & & 1 & 2 \\
\hline 3.4 & 3 & 10 & 5.0 & & 1 & 1 \\
\hline 3.5 & 1 & 7 & \multirow{3}{*}{\multicolumn{4}{|c|}{ (9) C'halkidike 1932}} \\
\hline 3.6 & 1 & 6 & & & & \\
\hline 3.8 & 2 & 5 & & & & \\
\hline 4.0 & 1 & 3 & 3.4 & & 5 & 85 \\
\hline 4.2 & 1 & 2 & 3.5 & & 2 & 80 \\
\hline \multirow[t]{4}{*}{4.4} & \multirow{4}{*}{ (7) Salinas 1963} & 1 & 3.6 & & 2 & 78 \\
\hline & & & 3.7 & & 6 & 76 \\
\hline & & & 3.8 & & 13 & 70 \\
\hline & & & 3.9 & & 12 & 57 \\
\hline 1.0 & 2 & 46 & 4.0 & & 5 & 45 \\
\hline 1. 1 & 4 & 44 & 4.1 & & 10 & 40 \\
\hline 1.3 & 4 & 40 & 4.2 & & 7 & 30 \\
\hline 1.4 & 1 & 36 & 4.3 & & 4 & 23 \\
\hline 1.5 & 1 & 35 & 4.4 & & 4 & 19 \\
\hline 1.6 & 7 & 34 & 4.5 & & l & 15 \\
\hline 1.8 & 3 & 27 & 4.6 & & 1 & 14 \\
\hline 1.9 & 2 & 24 & 4.7 & & 3 & 13 \\
\hline 2.0 & 4 & 22 & 4.8 & & I & 10 \\
\hline 2.1 & 2 & 18 & 4.9 & & 2 & 9 \\
\hline 2.2 & 2 & 16 & 5.0 & & 2 & 7 \\
\hline 2.3 & 4 & 14 & 5.1 & & 1 & 5 \\
\hline 2.4 & 2 & 10 & 5.6 & & I & 4 \\
\hline 2.5 & 2 & 8 & 5.7 & & I & 3 \\
\hline 2.6 & 2 & 6 & 5.8 & & l & 2 \\
\hline 2.8 & $\vec{l}$ & 4 & 6.2 & & 1 & 1 \\
\hline 2.9 & I & 3 & & & & \\
\hline 3.1 & 1 & 2 & \multirow{2}{*}{\multicolumn{4}{|c|}{ (10) W. Thessaly 1954}} \\
\hline 4.6 & 1 & 1 & & & & \\
\hline & & & 3.2 & & 13 & $\begin{array}{l}299 \\
286\end{array}$ \\
\hline & (8) Parkfield 1966 & & $\begin{array}{l}3.3 \\
3.4\end{array}$ & & $\begin{array}{r}1 \\
33\end{array}$ & $\begin{array}{l}280 \\
285\end{array}$ \\
\hline 2.0 & 36 & 173 & 3.5 & & 18 & 252 \\
\hline 2.1 & 18 & 137 & 3.6 & & 98 & 234 \\
\hline 2.2 & 16 & 119 & 3.7 & & 7 & 136 \\
\hline 2.3 & 20 & 103 & 3.8 & & 8 & 129 \\
\hline 2.4 & 13 & 83 & 3.9 & & 34 & 121 \\
\hline 2.5 & 15 & 70 & 4.0 & & 15 & 87 \\
\hline 2.6 & 9 & 55 & 4.1 & & 9 & 72 \\
\hline 2.7 & 7 & 46 & 4.2 & & 17 & 63 \\
\hline 2.8 & 5 & 39 & 4.3 & & 7 & 46 \\
\hline 2.9 & 7 & 34 & 4.4 & & 11 & 39 \\
\hline 3.0 & 10 & 27 & 4.5 & & 6 & 28 \\
\hline 3.1 & 5 & 17 & 4.6 & & 6 & 22 \\
\hline 3.2 & 2 & 12 & 4.7 & & 2 & 16 \\
\hline 3.3 & I & 10 & 4.8 & & 2 & 14 \\
\hline
\end{tabular}


'Table VIJI - Continued

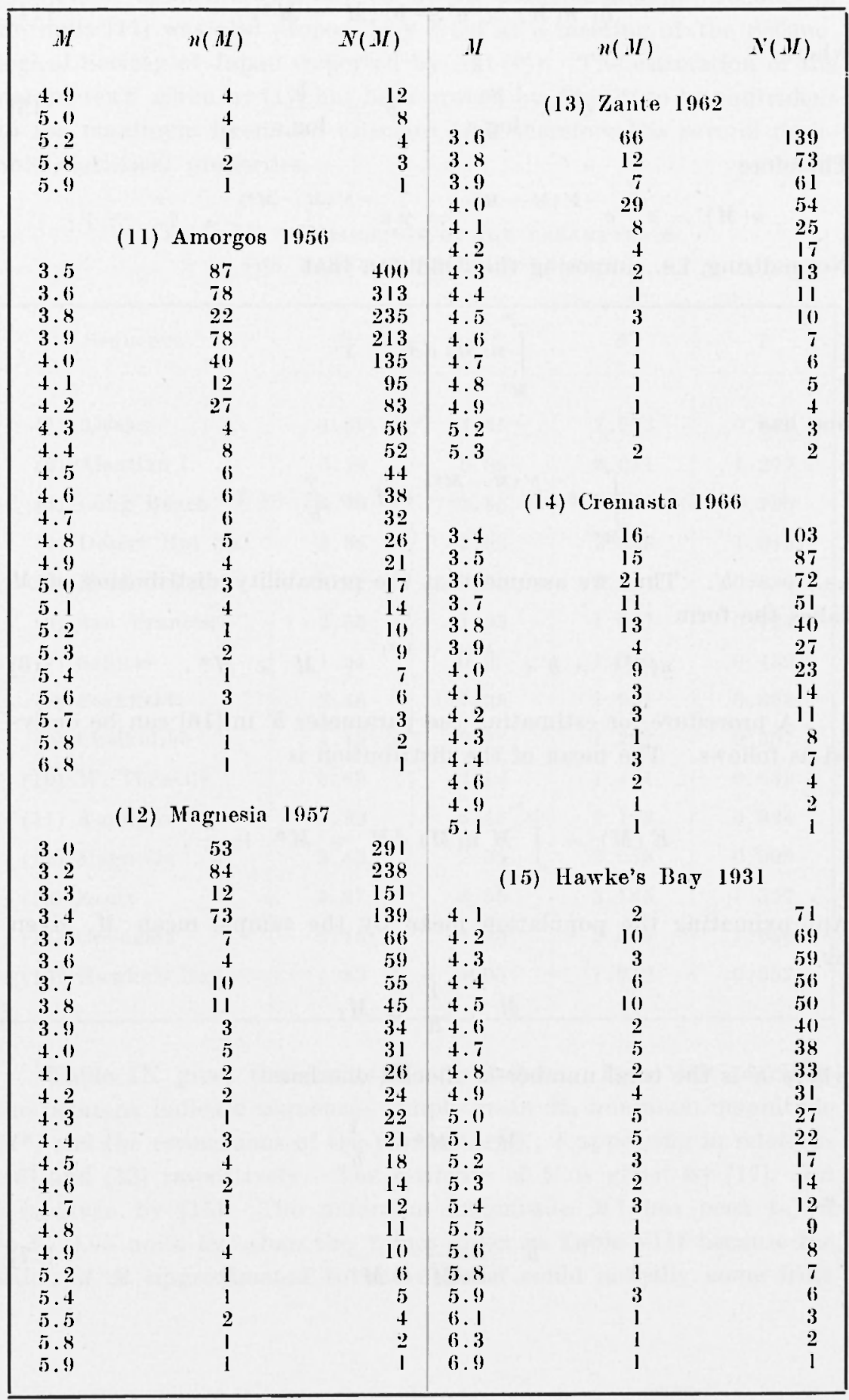


('onverting to natural logarithms one obtains

$$
\ln M(M)=a^{\prime}-b^{\prime}\left(M-M^{*}\right)
$$

where

$$
a^{\prime}=\frac{a}{\log e} \quad, \quad b^{\prime}=\frac{b}{\log e}
$$

Therefore

$$
u(M)=e^{a^{\prime}} e^{-U^{\prime}\left(M-M^{*}\right)}=\gamma e^{-U^{\prime}\left(M-M^{*}\right)}, e^{a^{\prime}}=\gamma .
$$

Normalizing, i.e., imposing the condition that

$$
\int_{M^{*}}^{\infty} n(M) d M=1
$$

one has

$$
\int_{M^{*}}^{\infty} \gamma e^{-b^{\prime}\left(M-M^{*}\right)} d M=\frac{\gamma}{b^{\prime}}=1
$$

i.e., $\gamma=b^{\prime}$. Thus we assume that the probability distribution of $M$ takes the form

$$
\|(M)=b^{\prime} e^{-h^{\prime}\left(M-w^{*}\right)}, \quad M \geqslant M^{*} .
$$

$\Lambda$ procedure for estimating the parameter $b^{\prime}$ in [16] can be derivad as follows. The mean of the distribution is

$$
W(M)=\int_{M^{*}}^{\infty} M U(M) d M=M^{*} ; i^{-} \frac{1}{b^{\prime}} .
$$

Approximating the population mean by the sample mean.$M$, given b.

$$
M-\frac{1}{K} \sum_{i=1}^{K} M_{i}
$$

where $K$ is the total number of shocks, one has

$$
\bar{M}=I^{*}+\frac{1}{b^{\prime}}
$$

i.e.,

$$
b^{\prime}=\frac{1}{M-M^{*}} .
$$


The above procedure is but a particular ase of the time-honored method of moments, introduced by K. Pearson and his school (-1). Formula [17] was also proposed by Utsu at a meeting of the Seismological Society of Japan (reported by Ali ( $\left.{ }^{26}\right)$ ). The estimation of the parameter $b^{\prime}$ given by [17] has been proved by $A k i(-6)$ to be equivalent to the maximum likelihood estimate, and therefore has several desirable statistical properties.

Table IX - Estimation of the PARAMETER b IN THE MAGNITUDE-FREQUENCY LAW.

\begin{tabular}{|c|c|c|c|c|c|}
\hline & Sequener & $y$ & $y^{*}$ & $b^{\prime}$ & $b$ \\
\hline (1) & Alaska & +.89 & 4.45 & 2.273 & 0.987 \\
\hline (2) & Aleutian I. & 6.19 & 5.85 & $2.9+1$ & 1.277 \\
\hline (3) & Iong Beach & 4.40 & $3.8 \pi$ & 1.818 & 0.790 \\
\hline$(4)$ & Desert Hot sp. & 3.38 & $2.9 \overline{5}$ & 2.326 & 1.010 \\
\hline (5) & Kern County & 4.44 & 3.95 & $2.11+1$ & 0.850 \\
\hline (6) & San Francis(e) & 2.55 & 1.95 & 1.667 & 0.724 \\
\hline$(7)$ & Salinas & 1.94 & 0.95 & 1.010 & $0 .+39$ \\
\hline (8) & Parkfield & 2.46 & 1.95 & 1.961 & 0.852 \\
\hline$(9)$ & Chalkidiko & +.13 & 3.35 & 1. 282 & 0.557 \\
\hline$(10)$ & IV. 'Thessaly & 3.83 & 3.15 & 1.471 & 0.639 \\
\hline (11) & $\Delta$ morgos & 3.92 & 3.45 & 2.128 & 0. .924 \\
\hline$(12)$ & Magnesia & $3 .+3$ & 2.95 & 2.083 & 0.905 \\
\hline (13) & Zante & 3.87 & 3.55 & 3.125 & 1.357 \\
\hline$(1+)$ & Cremasta & 3.75 & 3.35 & 2.500 & 1.086 \\
\hline$(1 \overline{5})$ & Ilawke's Bay & 4.83 & 4.05 & 1.282 & $0.5 \overline{7}$ \\
\hline
\end{tabular}

Table IX gives the results of calculations. From left to right, the columms indicate sequence, sample mean $\boldsymbol{H}$, minimum magnitude $I^{*}$, and the estimations of the parameters $b^{\prime}, b$ appearing in relations [16] and [13] respectively. The estimate of $b^{\prime}$ is given by [17], and $b$ is given by [15]. The minimum magnitude $M^{*}$ has been taken to be 0.05 units less than the values given in Table VIII berause the value of $M$ approximated to one decimal could actually come from 
anywhere in the interval $M \pm 0.05$. It can be seen that $b$ is usually slightly less than unity.

The basic idea for examining the observed fluctuations from the magnitude-frequency law is as in the case of the time distribution of aftershocks. Suzuki $\left({ }^{2}\right)$, among others, has argued that the number of shocks with $M \pm d M$ must follow a Poisson distribution. Accordingly, the problem is that of checking whether the observed deviation can be explained in terms of random fluctuations from the law.

It is more convenient to consider the cumulative distribution because individual large fluctuations in small intervals, possibly due to inaccurate magnitude determination, are smoothed out in this fashion, and moreover the normal approximation can be employed. The basic idea of the method is due to Suzuki $\left({ }^{2}\right)$. Some minor modifications have been introduced, and the normal approximation to the Poisson distribution, instead of the Poisson distribution itself, has been used.

From equation [16], it follows that the cumulative distribution function of magnitude has the form

$$
F(M)=\int_{-I}^{\infty} n(M) \quad d M=e^{-b^{\prime}\left(M-M^{*}\right)} .
$$

Assuming that the total number of aftershocks in a sequence, $K$, coincides with the theoretical value for $M=M^{*}$, the expected valuo of the cumulative frequency at various $M>M^{*}$ is given by

$$
\left.N(M)=K e^{-b^{\prime}(M-\cdots *}\right)
$$

which, when transformed by taking logarithms on both sides, is a straight line on semi-logarithmic paper, with slope equal to $-b$ if the logarithms are to the base 10 .

Sow, to each magnitude range there corresponds a Poissondistributed number of shocks. The cumulative number of shocks at a given magnitude $M$, therefore, is the summation of independent samples taken from each of the Poisson distributions corresponding to magnitudes greater or equal to $M$. According to the addition theorem for the Poisson distribution, such a cumulative number will also be Poisson-distributed. If the expected value is large enough, say, $N(M) \geqslant 10$ for all intervals, the Poisson distribution can be approximated by the normal distribution with mean $N(M)$ and standard deviation $\sqrt{ } N(M)$. It is then possible to calculate the fidncial in- 
terval beyond which flactuations are expected with a probability smaller than $5 \%$ (2.5\% on each side). The limits of the interval such that

$$
P\left\{\lambda_{1} \leqslant N \leqslant \lambda_{22}\right\} \simeq 0.95
$$

are, for the normal distribution, $E(N) \pm 2 D(N)$; i.e., in the present case, $N(M) \pm 2 \sqrt{N(M)}$.

Accordingly, the above quantities have been calculated at

$$
M_{\imath}=M^{*}+0.1 i, i=1,2, \ldots, k .
$$

Then, by joining all points of ordinates

$$
N\left(M_{i}\right)+2 \sqrt{N\left(M_{i}\right)} \text { and } N\left(M_{i}\right)-2 \sqrt{N\left(M_{i}\right)},
$$

respectively, one obtains a confidence band which should contain

\begin{tabular}{|c|c|c|c|}
\hline Serguence & $\begin{array}{l}\text { Total number } \\
\text { of data points }\end{array}$ & $\begin{array}{l}\text { Number of } \\
\text { points outside } \\
\text { conf. limits }\end{array}$ & $\begin{array}{l}\% \text { Points } \\
\text { outside }\end{array}$ \\
\hline (I) Alaskia & 15 & 4 & $26.7 \%$ \\
\hline (2) Alentian I. & 11 & 0 & 一 \\
\hline (3) Long Beach & 12 & 2 & $16.7 \%$ \\
\hline (4) Desert IIot sp. & 9 & 0 & 一 \\
\hline (5) Kern County & 15 & 0 & 一 \\
\hline (6) San Franciseo & 17 & 0 & - \\
\hline (7) Salinas & 16 & 0 & - \\
\hline (8) Parkfield & 15 & 0 & - \\
\hline (9) Chalkidike & 17 & 2 & $11.8 \%$ \\
\hline (II) 11 . Thessaly & 24 & 14 & $58.3 \%$ \\
\hline (II) Amorgos & 18 & 1 & $5.6 \%$ \\
\hline (12) Magnesia & 17 & 3 & $17.6 \%$ \\
\hline (13) Zante & 9 & 2 & $99.2 \%$ \\
\hline (14) Cremasta & 10 & 0 & $\ldots$ \\
\hline (15) IIawke's Bay & 16 & 0 & 一 \\
\hline
\end{tabular}
approximatiely $95 \%$ of the data points if they come from a population

Table $\mathrm{X}$ - Validity OF THE MAGSTUDE-FrequeNCY LaW 
whose expected value is given by the magnitude-frequency law as expressed by [18]. The rightmost interval (say, from.$M$, to $\infty$ ) has always be chosen in such a way that $N(I K) \geqslant 10$.

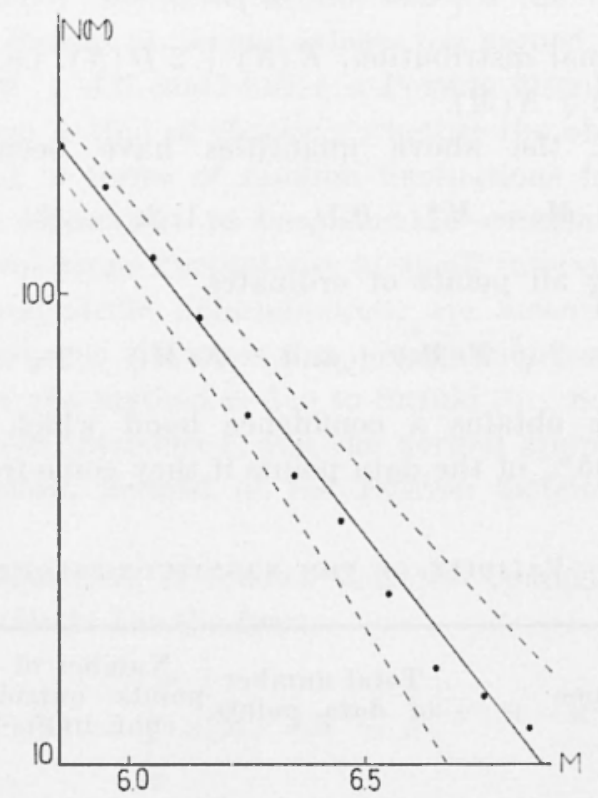

Fig. 7. - Magnitude-frequeney distribution: Aleutian Islands 1957.

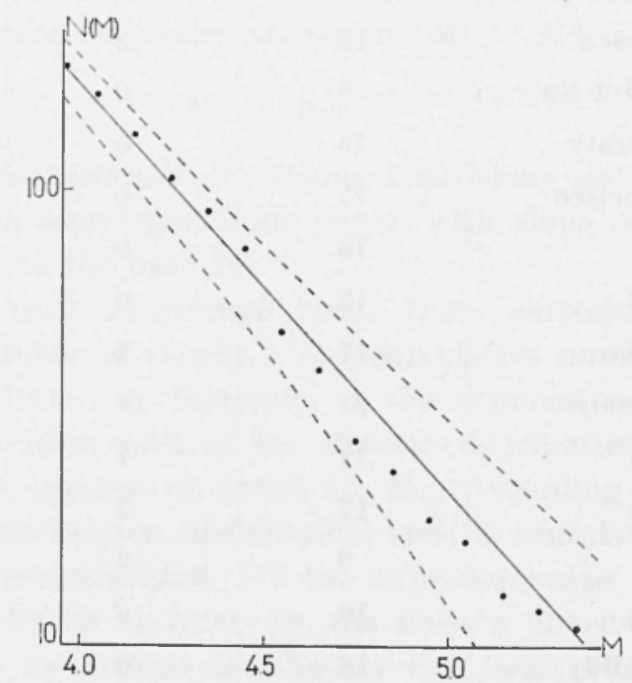

Fig. 8. - Magnitude-frequeney distribution: Kern County 1952. 


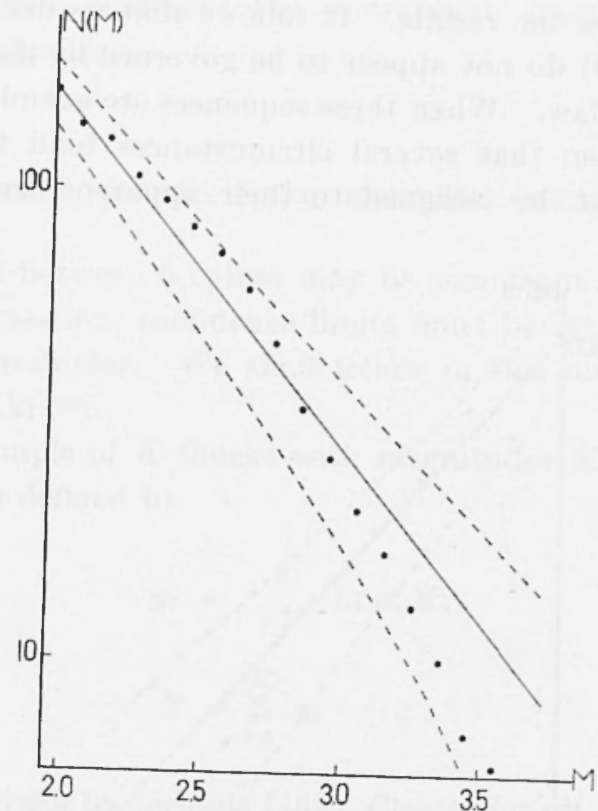

Fig. 9. - Magnitude-frequency distribution: San Franeiseo 1957.

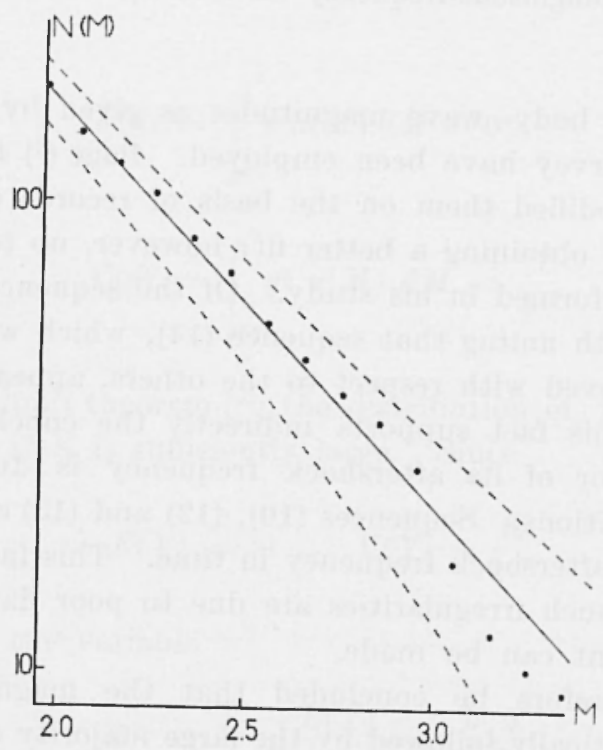

Fig. 10. - Magnitude-frequeney distribution: Parkfield 1966. 
Table $\mathrm{X}$ gives the results. It follows that sequences (1), (3), (9), (10), (12) and (13) do not appear to be gorerned by the assumed magnitude-frequency law. When these sequences are examined one by one, however, it is seen that several circumstances tend to decrease the weight that must be assigned to their apparent irregularity. For

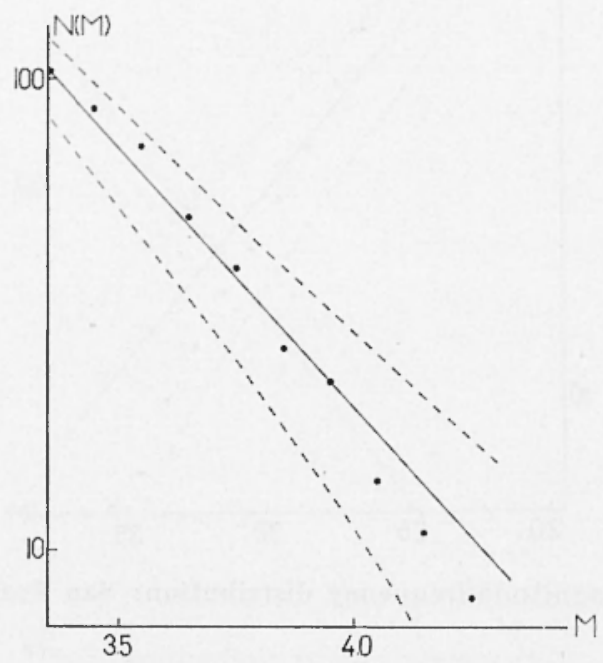

Nig. 11. - Magnitude-frequency distribution: Cremasta 1966.

sequence (1) the body- wave magnitudes as given by the U.S. Coust. and Geodetic Survey have been employed. Page $\left(^{3}\right)$ found them inaccurate and modified them on the basis of records of five selected stations, thereby obtaining a better fit; however, no test on the fluctuations was performed in his study. Of the sequences oceuring in Greece, it is worth noting that sequence (14), which was studied with a network improved with respect to the others, appears to follow the assumed law; this fact supports indirectly the conclusion that the irregular behavior of its aftershock frequency is due to changing local stress conditions. Sequences (10), (12) and (13) are also irregular with respect to aftershock frequency in time. This fact points to the likelihood that such irregularities are due to poor data, although no definite statement can be made.

It can therefore be concluded that the magnitude-frequency law [18] is statistically followed by the large majority of the sequences under consideration. Figures 7 to 11 give some examples; the lo- 
garithmic ordinate represent the cumulative frequency, the linear abscissa the magnitude.

Confidence Limits on the Frequenct Paraneter.

Differences between $b$-values may be significant or not. In order to decide the question, confidence limits must be set on the estimated value of the parameter. We shall follow in this matter a procedure suggrested by $\Lambda$ ki ( $\left.{ }^{26}\right)$.

Given a sample of $K$ shocks with magnitudes $M_{i}, i=1, \ldots, k$, let $y_{i}$ and $Y$ be defined by

$$
\begin{aligned}
& y_{i}=\frac{\partial}{\partial b^{\prime}} \ln n\left(M_{i}\right) \\
& Y=\sum_{i=1}^{K} y_{i}
\end{aligned}
$$

where $n(M)$ is given by formula [16]. Clearly for all $i$,

$$
y=\frac{1}{b^{\prime}}-M+M *
$$

and therefore

$$
\begin{aligned}
& E(y)=\int_{M^{*}}^{\infty} y n(M) d M=0 \\
& \mathrm{~V}^{\prime}(y)=\int_{M^{*}}^{\infty} y^{2} n(M) d M=\frac{1}{b^{\prime 2}}
\end{aligned}
$$

By the central limit theorem (24) the distribution of $Y$ will be approximately normal if $K$ is sufficiently large. Since

$$
E(Y)=0, \quad V^{Y}(Y)=\frac{K}{\ell^{\prime 2}}
$$

it follows that the variable

$$
Y^{*}=\frac{Y-E(Y)}{D(Y)}=\frac{b^{\prime} Y}{\sqrt{K}}
$$


is approximately normally distributed with mean 0 and standard deviation 1 ; therefore

$$
I^{\prime}\left\{-1.96 \leqslant Y^{*} \leqslant 1.96\right\}=0.95 \text {. }
$$

Accordingly, the $95 \%$ confidence limits on $b^{\prime}$ are obtained by solving the inequality

$$
-1.96 \leqslant \frac{b^{\prime} Y}{\sqrt{K}} \leqslant 1.96
$$

which grives

$$
-1.96 \leqslant \frac{b^{\prime}}{\sqrt{K}} \sum_{i=1}^{K}\left(\frac{1}{b^{\prime}}-M_{i}+M^{*}\right) \leqslant 1.96
$$

i.e.,

$$
\frac{1-1.96 / \sqrt{K}}{M-M^{*}} \leqslant b^{\prime} \leqslant \frac{1+1.96 / \sqrt{K}}{M-M^{*}}
$$

Table XI - ConfIDENCE LIMITS ON THE FREQUENCY PARAMETLR.

\begin{tabular}{|l|l|}
\hline \multicolumn{1}{|c|}{ Sequence } & $95 \%$ Confidence limits \\
\hline (2) Alentian I. & $1.102 \leqslant b \leqslant 1.452$ \\
(4) Desert Hot Sp. & $0.770 \leqslant b \leqslant 1.250$ \\
(5) Kern County & $0.757 \leqslant b \leqslant 1.015$ \\
(6) San Francisco & $0.612 \leqslant b \leqslant 0.836$ \\
(7) Salinas & $0.312 \leqslant b \leqslant 0.566$ \\
(8) Parkfield & $0.725 \leqslant b \leqslant 0.979$ \\
(11) Amorgos & $0.833 \leqslant b \leqslant 1.015$ \\
(14) Cremasta & $0.876 \leqslant b \leqslant 1.296$ \\
(15) Hawkes Bay & $0.427 \leqslant b \leqslant 0.687$ \\
\hline
\end{tabular}

Table XI summarizes the results for the 9 sequences where the assumed magnitude-frequency law appears to hold. According to usage, the parameter $b$, instead of $b^{\prime}$, has been employed. It ran be seen that the $b$-values cluster around the interval $0.8-1.0$. 
Nlthough sequence (2), which occurred along an active island arc, shows an anomalously high value of the frequency parameter, the sample size is too small to support the contention that $b$ has some geotectonic significance.

\section{Conclusion.}

The basic statistical laws describing the phenomenology of aftershock sequences are confirmed by the present study. These laws are as follows:

(1) Aftershock sequences are generally crustal avents, although deeper ones also occur;

(2) The frequency of aftershock occurrence within the same sequence decays in time according to the law

$$
u(t)=\alpha t^{-\beta}, \quad t \geqslant 100
$$

where the decay parameter $\beta$ is approximately equal to, or slightly greater than, unity;

(3) The aftershock magnitudes, apart from individual fluctuations, show stability in time to the end of the sequence;

(4) The frequency-distribution of magnitude in a sequence is of exponential form

$$
N(M)=K e^{-b^{\prime}\left(M-M^{*}\right)}
$$

where the frequency parameter $b=b^{\prime} \log e$ is usually slightly less than unity

The importance of the mode of grouping the data in a statistical analysis makes it desirable to introduce a standardized procedure. Furthermore, an appropriate statistical method must be employed, and the hypotheses involved must be checked. A systematic treatment of clata greatly increases the reliability of the results.

It also turns out that the least squares method, when the observed values are uncorrelated, yields rather satisfactory results even if the conditions for its theoretical validity are not met. 


\section{ACKNOWLEDGEMENTS.}

The anthor wishes to express his thanks to Profensor A. L. Scheidegger of the University of Illinois at Urbana, who kindly discussed some questions which arose during the preparation of this paper and reviewed the manuscript. Sumerical calculations were performed on the University of Illinois IBMI Spstem/360 computer, operating under a grant from the United States National Science Foundation. The support received from this agency is gratefully acknowledged.

\section{REFERENCES}

(1) PaGe R., Focal Depths of Aflershocks, "J. Geophys. Res.", 73, 3897 . 3903 (1968).

(2) Suzuki Y/., A Statistical Study of the Occurrenee of Small Earthqualies, III, “Sci. Rep. Tohoku Univ., 5th Series, Geophys.", 10, 15.27 (1958)

(3) PAGE R., Aflershochs and Microaftershocks of the Great Alasha Earthquake of 1964. "Bull. Seism. Soc. Am.", 58, $1131-1168$ (1968).

(4) DUdA S.J., Phänomenologische Untersuchung einer Nachbebenserie aus dem Gebiet der Aleuteninseln. "Freib. Forschungshefte". G-132, 5-90 (1962).

(5) Beniofr H., Earlhqualies and Rock Creep, I. "Bull. Seism. Soc. Am.", 41, $31-62$ (1951).

(6) Richter C. F., Aldex C. R., and Nordquist .I. M., The Desert IIol Springs Earthquakes and Their Tectonic Environment, "Bull. Seism. Soc. Am.", 48, 315-337 (1958).

(7) Ricirter (. F., Foreshocks and Aftershocks, in Earthqualies in fern County, Galifornia, during 195:, "Bull. Cal. Div. Mines.", 171, 177197 (1955).

(") Tocmen D., Seismographic Results from the 19:j, San Franciseo Earthquake, in San Franciseo Earlhquakes of March 195\%, "Cal. Div. Mines sp. Re1.", 57, 59-7l (1959).

${ }^{(9)}$ Toras A., A Study of the Aftershochs and Foeal Mechanism of the Salinas. IValsonville Earthquales of iugust 31 and September 14, 1963, "Bull. Seism. Soc. Am.", 55, 85-106 (1965).

(10) MeEvid.y T. V., Bakux W. H.. and Casaday K. B., The Parkfield, California, Earthquales of 1966, "Bull. Seism. Soc. Am.", 57, 122 L. $1244(1967)$.

(") Papazachos B., Delibasis N., Jiapis N., Moumoudidis G.. and Puncaru G., Aftershock Sequences of Some Targe Earthqualies in the Region of Greece, "Alm.. Geofisica", 20, 1.93 (1967). 


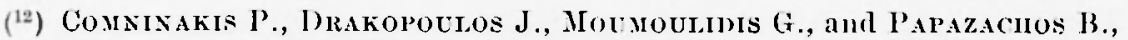
Foreshock and Aftershock sequences of the Cremusta Earthqualie and Their Relation to the Waterloading of the Cremasta Artificial Lake, "Ann. Geofisica". 21, 39-7] (1968).

${ }^{(13)}$ Mogr K., On the Time Distribution of Aftershocks Accompanying the Recent Major Earthquates in and near Japan, "Bull. Earthq. Res. Inst. ". 40. 107-124 (1962).

(14) Lonsitz C., Magnitude Stability in Earlhquale Sequences, "Bull. Seism. Soc. $A \mathrm{~m} . ", 56,247-249(1966)$.

${ }^{(15)}$ Gutendeic B., and Riciter C. F., Seismicity of the Earth and Associnted Phenomena, 2nd ed., Princeton Univ. Press., Princeton (1954).

${ }^{(16)}$ Matuzawa T., Study of Earthquakes, Cno Shoten, Tokio (1964).

(17) B.ITII M., and BExiofF II., The Aftershock Sequence of the Kamchatia Earlhquake of November 4, 19.5\%, "Bull. Seism. Soc. Am.", 48. 1-15 (1958).

$\left.{ }^{18}\right)$ IosiF T', and RAwU C., Elastic Strain Characteristics in the Deep-Focus Earthquakes of the Francea Region, "Sturl. Cere. Astr. Seism.", 2. 269-285 (1961), [in Romanian].

(19) Jukк A. A.. The Aftershock Sequence of the Dzhurm Deep-Focus Eurthquake of March 14, 1965, "Izv. Earth. Plyys.", 5, 83-85 (1968) fin Russian].

$\left.{ }^{(20}\right)$ JeFrneys Sir II., Aftershocks and Periodicity in Earthqualies, "cierl. Beitr. Ceophys.", 53, $111-139$ (1938).

${ }^{(21)}$ UTsu T., On the Nature of Three Alaskan Aftershock Sequences of 1957 and 1958, "Bull. Seism. Soc. Am.", 52, 279-297 (1962).

${ }^{(22)}$ Graybil.t. F. A., An Introduction to Linear Stalistical IIodels, Vol. I, MeGraw-Hill, New York (1961).

${ }^{(23)}$ Yule G. L., and Kexdat. M. G., An Introduction to the Theory of statistics, 12th ed., Griffin, Jondon (1940).

${ }^{(21)}$ Cranúr Il., Mathematical Methods of Statistics, Princeton L'niv. Press, Princeton (1946).

${ }^{(25)}$ Ralston A., A First Course in Numerical Analysis, McGraw-Hill, New York (1965).

${ }^{(26)}$ A $\mathrm{ki}$ K., Macimum Likelihood Estimate of $b$ in the Formula logr $N=a-$ b.1I and its Confidence Timits, "Bull. Farthq. Res. Inst.", 43, 237. 239 (1965). 